\title{
Potential Risk of Vapour Cloud Explosion in FLNG Liquefaction Modules
}

\author{
Sayyoon Park, Byongug Jeong *, Byung Suk Lee, Selda Oterkus, Peilin Zhou \\ Department of Naval Architecture, Ocean and Marine Engineering, University of Strathclyde, 100 \\ Montrose Street, Glasgow, G4 OLZ, UK \\ *corresponding author; e-mail: byongug.jeong@strath.ac.uk, phone: +44(0)7425694809
}

\begin{abstract}
Floating Production Storage and Offloading vessels have been in operation for four decades and there are now well over 250 vessels in existence, but their gas equivalent floating liquid natural gas plants kwon as FLNGs are still very new. Consequently designs and arrangement of top-side process units are still evolving and their safety has yet to be fully and objectively evaluated. This paper explores the probability of occurrence of accidents leading to vapour cloud explosion at one of the topside liquefaction modules of an FLNG. The worst possible scenario with the maximum tolerable probability is identified and the impact of the corresponding vapour cloud explosion is estimated. The strength of the structures supporting the neighbouring modules was examined using finite element analysis to determine if the accident has a potential of escalating to neighbouring modules.

It is found that the current levels of safety gaps between the liquefaction modules may be insufficient for the structural arrangement in place. It is thought that a new structural design using circular pipes as the structural elements instead of the I-beams may enhance the integrity of the top-side supporting structures against the impact of potential vapour cloud explosion. The effectiveness of the new structure is demonstrated by comparing it to the conventional supporting structure using I-beam members. This also implies that, by using pipe elements, the safety gaps can be reduced, thus making it possible to optimise the topside arrangement more easily.
\end{abstract}

Keywords: FLNG, risk assessment, safety, safety gap, structural strength, vapour cloud explosion, safety evaluation 


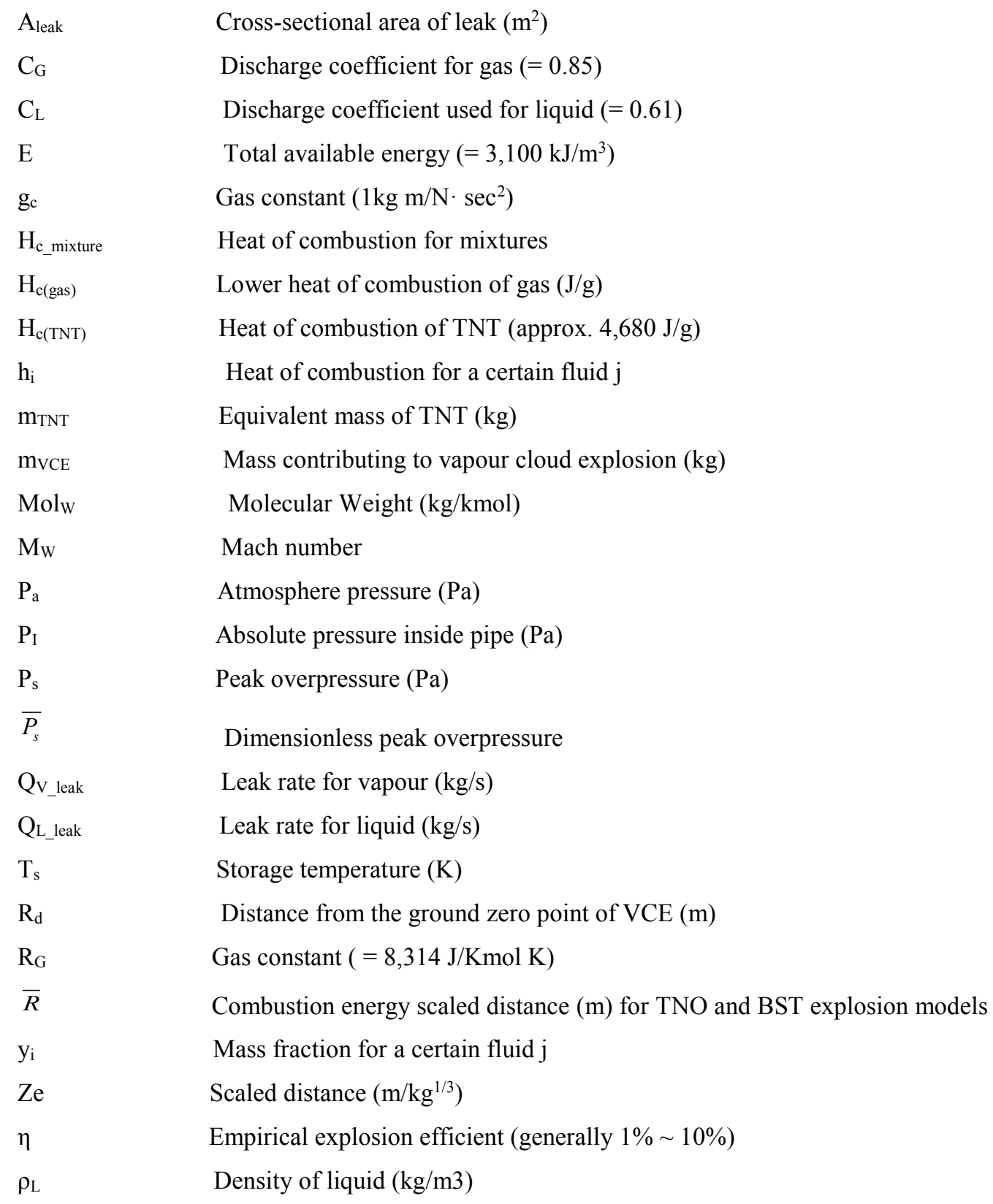




\section{Introduction}

Offshore gas production and processing has mostly relied on permanent or semi-permanent bottomsupported structures. The initial investment required for such facilities is very high, and most of these structures cannot be reused when the gas field they serve is exhausted. In the current climate of low energy price developing offshore gas fields which are getting smaller using the bottom-supported structure is becoming highly uneconomical. Furthermore, much of the processing of the produced natural gas is usually carried out on shore. However, this requires extensive facilities on shore areas and the process of obtaining permission to build such facilities is long and difficult.

These problems can largely be overcome when floating production units, known as LNG-FPSO (liquefied natural gas floating production storage offloading unit) or FLNG (floating liquid natural gas unit), are used. Since their first appearance in 2011, the total annual production capacity of FLNGs across the world reached 168.3 million tonnes as of early 2015 (IGU, 2015).

The topside of a typical FLNG consists of compact structures comprising several chemical processing units for separation of gas from oil, gas liquefaction, LNG storage, offloading and so forth. Consequently the probability of the occurrence of an unwanted release of LNG (or natural gas) can be relatively high. Since the released fluid is likely to be trapped within these compact structures, an accidental ignition will lead to critical consequences associated with vapour cloud explosion (VCE), possibly resulting in the accident escalating to neighbouring process systems.

In an effort to prevent the impact of such incidents from spreading to neighbouring structures, the concept of safety gap between the topside LNG process modules has been introduced. For instance, the LNG liquefaction modules installed on the world's largest FLNG unit were arranged in such a way that they are separated from each other by a safety gap of $12.5 \mathrm{~m}$ to $20 \mathrm{~m}$ (Li J. et al, 2016). Despite such precautions, it appears that the supporting structures of the liquefaction units are not specially strengthened against potential VCE (personal interview with one of the designers of the vessel). Moreover, it can be argued that the extent of the safety gaps are determined somewhat arbitrarily.

The concept of FLNG is still new and the safety of the top-side system has yet to be fully verified. As a result, the existing relevant standards, such as NORSOK and API, and classification rules are mostly limited to the provisions of general guidelines. No systematic investigation into the safety of FLNG has been undertaken to date, and the closest previous studies were on the risk of semi-submersible rigs and FPSOs (Jin, 2015; Bai, 2016; Sohn et al, 2013; Faber et al, 2012; Heredia-Zavoni et al, 2012).

Dan (Dan et al, 2014) has investigated individual risk associated with fire and explosion caused by the top-side liquefaction process of FLNG. Chae (Chae, 2016) explored the changes in risk characteristics depending on different selection of liquefaction systems. Despite these studies, the safety of FLNG, especially structural design and arrangement of top-side units, has rarely been evaluated in a systematic 
way. Spouge (1999) and Vinnem (2007) provided general guidance for quantitative risk assessment of offshore oil and gas units.

In terms of structural analysis associated with offshore fire/explosion, there have been extensive studies. Paik et al. (2014) has introduced a new procedure for the nonlinear structural response analysis of offshore installations in explosions. Paik et al. (2016) investigated hydrocarbon risks of hydrocarbon explosion and fire for offshore units. In addition, structural integrity against gas explosion have been investigated by Czujko and Paik (2015) and Sohn et al. (2016). Eslami-Majd and Rahbar-Ranji (2015) has investigated the effect of corrosion on the structures against explosion.

The work presented in this paper attempted to compare the safety of supporting structures for liquefaction modules with a potential VCE at a neighbouring module, providing a generic understanding of adequacy or inadequacy of the current practices. In addition, it would suggest practicable recommendations for future designs/arrangements of FLNG top-side liquefaction modules. 


\section{Approaches adopted}

The objective of this study is to investigate the structural safety of LNG liquefaction modules against potential VCE. This is achieved by identifying the most severe explosion scenario with the minimum tolerable probability of occurrence. Existing standards and guidelines give different tolerability criterion, but the present study adopted the level of 10-3 per year as guided by the UK Health and Safety Executive (HSE) (Holden, 2014).

The scenarios were converted to corresponding explosion overpressure values and this was then made into an exceedance diagram from which the overpressure corresponding to the tolerable frequency of occurrence was identified as shown in Fig. 5 in Section 3.3.

Finite element analysis is carried out on the supporting structures of the liquefaction modules to determine if they have sufficient strength to withstand the overpressure due to the VCE. The approaches used in this study are summarized as below.

\section{1. $\quad$ System grouping}

For a complex system the risk level depends on the location of the initial leak and different working conditions. In order to deal with such complexity effectively, the system can be split into several groups based on fluid phase, compositions, operating pressure and temperature (Jeong et al., 2016). The risk of each group can be assessed separately and then summed to produce the overall risk of the whole system.

\subsection{Frequency analysis}

In order to identify all possible routes leading to VCE and its frequency, event tree analysis (ETA) technique is used as shown in Fig. 1 (Dan et al, 2014). Following the scenarios in ETA, the VCE is assumed to occur when a leakage e is sufficiently developed and vaporized (Woodward and Pitbaldo, 2010). Depending on the surrounding condition, if it is largely open or congested, explosion or flash fire can occur. Some use a congestion rate of $50 \%$ which makes the probability of explosion and flash fire $50 \%$ each once the ignition is delayed (Dan et al., 2014). On the other hand, an immediate ignition may lead to jet fire or pool fire, rather than explosion, depending on fuel phase (Woodward and Pitbaldo, 2010). Despite this, the focus of this study is to investigate the design and arrangement of each supporting structures of LNG liquefaction module.

In order to estimate the frequency of VCE, this paper is relied upon generic data widely used for investigating hydrocarbon release associated with LNG process equipment in offshore and chemical 
industries. According to the DNV Leak Frequency Datasheets (DNV, 2012) the frequency of an initial leak from the liquefaction units are analysed for different leak hole sizes: $3 \mathrm{~mm}, 10 \mathrm{~mm}, 50 \mathrm{~mm}$ and full $(100 \mathrm{~mm})$. The probability of immediate ignition is estimated according to DNV model (DNV, 2012) as shown in Table 1 with which the probability of immediate ignition is estimated based on the fuel phase and release rate. On the other hand, the probability of delayed ignition for LNG leak and gas is estimated according to OGP model (OGP, 2010) as shown in Table 2 which uses two different models depending on whether the fuel is gas or liquid. Similar to DNV model, release rate is importantly used to estimate the probability of delayed ignition.

\subsection{Consequence analysis}

Consequence analysis is focused on the investigation of the magnitude of the overpressure caused by VCE imposing on which is exposed to the supporting structure of LNG liquefaction modules. In order to estimate the impact of VCE three different analytical models are used: TNT equivalent method, TNO multi-energy and the Baker-Strehlow-Tang model (BST) (Woodward and Pitbaldo, 2010).

\subsubsection{Calculation of leak rate}

The leak rate depends on leak hole size and working conditions. For liquid leak calculation, Eq. (1) can be applied (DNV, 2012).

$$
\mathrm{Q}_{\mathrm{L}_{-} \text {leak }}=\mathrm{C}_{\text {liquid }} \mathrm{A}_{\text {leak }} \sqrt{2 \rho_{\mathrm{L}}\left(\mathrm{P}_{\mathrm{I}}-\mathrm{P}_{\mathrm{a}}\right)}
$$

The gas leak rate was estimated with respect to the two specific flow regimes: sonic flow for higher internal pressures and subsonic flow for lower pressures. Eq. (2) defines the pressure at which the flow regimes change from sonic to subsonic (Yoon et al., 2008).

$$
\left(\frac{\mathrm{P}_{\mathrm{a}}}{\mathrm{P}_{\mathrm{I}}}\right)_{\mathrm{CR}}=\left(\frac{2}{\gamma+1}\right)^{\frac{\gamma}{\gamma-1}}
$$

For sonic flow, leak rate can be calculated as:

$$
\mathrm{Q}_{\mathrm{V}_{-} \text {leak }}=\mathrm{C}_{\text {gas }} \mathrm{A}_{\text {leak }} \mathrm{P}_{\mathrm{I}} \sqrt{\frac{\gamma \mathrm{Mol}_{\mathrm{W}}}{\mathrm{R}_{G} \mathrm{~T}_{\mathrm{S}}}\left(\frac{2}{\gamma+1}\right)^{\frac{(\gamma+1)}{(\gamma-1)}}} \text { for } \frac{\mathrm{P}_{\mathrm{a}}}{\mathrm{P}_{\mathrm{I}}} \leq\left(\frac{\mathrm{P}_{\mathrm{a}}}{\mathrm{P}_{\mathrm{I}}}\right)_{\mathrm{CR}}
$$


For subsonic flow, leak rate can be calculated as:

$$
\mathrm{Q}_{\mathrm{V}_{\text {lleak }}}=\mathrm{C}_{\text {gas }} \mathrm{A}_{\text {leak }} \mathrm{P}_{\mathrm{I}} \sqrt{\frac{\gamma \mathrm{g}_{\mathrm{C}} \mathrm{Mol}_{\mathrm{W}}}{\mathrm{R}_{G} \mathrm{~T}_{\mathrm{S}}} \frac{\gamma}{\gamma-1}\left[\left(\frac{\mathrm{P}_{\mathrm{a}}}{\mathrm{P}_{\mathrm{I}}}\right)^{\frac{2}{\gamma}}-\left(\frac{\mathrm{P}_{\mathrm{a}}}{\mathrm{P}_{\mathrm{I}}}\right)^{\frac{(\gamma+1)}{\gamma}}\right]} \quad \text { for } \frac{\mathrm{P}_{\mathrm{a}}}{\mathrm{P}_{\mathrm{I}}}>\left(\frac{\mathrm{P}_{\mathrm{a}}}{\mathrm{P}_{\mathrm{I}}}\right)_{\mathrm{CR}}
$$

The total leak amount is calculated by multiplying the leak rate by the leak duration.

\subsubsection{Calculation of VCE impact}

\section{TNT equivalency model}

TNT equivalent explosion model can be used to calculate the overpressure developing at specified distances. Eqs (5-8) describes associated formulae (Baker, 1973; Crowl and Louvar, 1990). The total energy engaged in the VCE was initially converted into the equivalent mass of TNT by

$$
\mathrm{m}_{\mathrm{TNT}}=\frac{\mathrm{m}_{\mathrm{VEC}} \eta \Delta \mathrm{H}_{\mathrm{c} \_ \text {mixture }}}{\Delta \mathrm{H}_{\mathrm{c}(\mathrm{TNT})}}
$$

The total combustion energy of mixtures was calculated with

$$
\Delta \mathrm{H}_{\mathrm{c}_{-} \text {mixture }}=\sum_{\mathrm{j}=1}^{\mathrm{K}} \mathrm{y}_{\mathrm{j}} \mathrm{h}_{\mathrm{j}}
$$

Based on the experiments, empirical explosion efficiency is generally set between $1 \% \sim 10 \%$. In order to investigate the most stringent condition, the present study adopted $10 \%$. The scaling parameter, $\mathrm{Ze}$, can be calculated as

$$
\mathrm{Ze}=\frac{\mathrm{R}_{\mathrm{d}}}{\mathrm{m}_{\mathrm{TNT}}^{\frac{1}{3}}}
$$

This parameter was then used to estimate the overpressure, $\mathrm{P}_{\mathrm{s}}$

$$
\mathrm{P}_{\mathrm{s}}=573 \times \mathrm{Ze}^{-1.685}(\text { in } \mathrm{KPa})
$$


This model is increasingly acknowledged as a more reasonable alternative to TNT (Woodward, 2010). The overpressure value can be calculated as (Alonso et al., 2006),

$$
\mathrm{P}_{\mathrm{s}}=\overline{\mathrm{P}_{\mathrm{s}}} \mathrm{P}_{0}
$$

Then, the dimensionless peak pressure can be calculated as

$$
\overline{\mathrm{P}_{\mathrm{s}}}=\left\{\begin{array}{cc}
1 & , 0.23<\overline{\mathrm{R}}<0.5 \\
4.06 \times 10^{-1} \overline{\mathrm{R}}^{-1.2} & , 0.5<\overline{\mathrm{R}}<100
\end{array}\right.
$$

Here $\bar{R}$ is the combustion energy scale distance, which is merely a convention to be readily converted to other forms of normalization.

$$
\overline{\mathrm{R}}=\mathrm{R}_{\mathrm{d}}\left(\frac{\mathrm{P}_{0}}{\mathrm{E}}\right)^{\frac{1}{3}}
$$

\section{Baker-Strehlow-Tang (BST) model}

The BST model is similar to the TNO Multi-Energy Model. Eq. (11) is used to obtain the combustion energy scale distance (Melton and Marx, 2009; Woodward and Pitbaldo, 2010). The curves used in the BST model, shown in Fig. 2, are based on numerical modelling of constant velocity flames and accelerating flames spreading through spherical vapour clouds.

Mw, referred to as 'mach number', is determined by a combination of flame expansion dimension, fuel reactivity and obstacle density as shown in Table 3. Baker (Baker et al, 1994) suggested the fuel reactivity for methane to be categorised 'low'. Taking into account of the 'high' obstacle density (denser than $5.7 \%$ of total space volume) in the topside and 2.5-dimension flame expansion direction, the $\mathrm{Mw}$ suggested by the model for the case studied here is 0.5 (Melton and Marx, 2009; Woodward and Pitbaldo, 2010).

For investigating worst-case scenarios, this study assumes the total amount of leaked fuel is involved in the VCE, and this amount, $\mathrm{m}_{\mathrm{VCE}}$, is equal to the leakage rate calculated from Eqs (1-4) multiplied by the total leakage duration. The leakage duration may vary depending on safety systems on topside units. The duration will be discussed in Section 3.

\subsection{Investigating structural safety}


This step is for investigating the adequacy of the structures based on present design practices using the estimated impact of VCE at the distance of the safety gaps. Reflecting the fact that different leak scenarios give rise to different impact of VCE, frequency analysis was carried out to derive an exceedance curve between frequency and overpressure on the neighbouring structures. It then determines the critical level of overpressure by applying tolerable frequency level of 1.0E-3/year. Once the critical degree of overpressure is determined, finite element analysis (FEA) is used to investigate the effect of the critical overpressures on the structures. If the equivalent stress of the structure against the overpressure is found to be higher than that allowed by the classification rules for the material, additional safety measures need to be introduced. One such safety measure can involve a new structural design using pipe elements instead of I beams. The effectiveness of such a structural design is investigated, and the results are compared to the conventional I-beam structures. This will certainly highlight the adequacy or otherwise of the current practices for setting up safety gaps between LNG reliquefaction modules. In addition, it may also point to a possible simple improvement measure to enhance the safety of FLNGs.

\section{Case study}

\subsection{The case ship}

The study was carried out on the topside area of a developed concept FLNG design ( $\mathrm{Li}$ et al, 2016). The vessel is 480 metres in length, 75 metres in breadth (Fig. 3) and the vessel can process up to 3.6 million tons of gas annually.

\subsection{System description and grouping}

Fig. 4 shows the liquefaction process, known as DMR (dual mixed refrigerant) cycle, fitted to each liquefaction module of the vessel (Lee et al., 2012). The system mainly consists of two coolers using sea water, three compressors, four heat exchanger, five expansion valves and two phase separators. It has a two-stage liquefaction process utilizing mixed refrigerants (methane, ethane, propane, butane, nitrogen, etc.) for pre-cooling, and main refrigerants (natural gas) for liquefaction.

According to the operational characteristics, the overall liquefaction system can be spilt into 31 groups in total and the details are listed in Table 4 (Lee et al., 2012). The numbers in circles in the figure denote the group numbers in Table 3. 


\subsection{Frequency of critical overpressure}

Four leak hole sizes were selected to represent the leak dimensions (3, 10, 50 and $100 \mathrm{~mm}$ diameter). Using DNV Database described in Section 2.1, the initial frequencies of fuel leak for the four representative leak hole sizes were calculated as shown in Table 5, resulting in 124 case VCE scenarios in total. Then, the estimated initial leak frequency for each scenario was input to ETA described with Fig. 2 to estimate the probability of VCE.

The leakage rate for each hole size was then calculated by using Eqs (1-4) and the results are summarised in Table 6. It was assumed that the flammable mass, $\mathrm{M}_{\mathrm{VCE}}$, involved in the VCE is equivalent to the total released amount from each leak scenario.

To investigate the impact of VCE on the supporting structures for LNG liquefaction modules, VCE was assumed to be initiated in module 9. According to the original topside design of the vessel (Fig. 5), three different safety gaps were used: $20 \mathrm{~m}$ (Case 1) for Module 11, $15 \mathrm{~m}$ (Case 2) for Module 10 and 12.5 m (Case 3) for Module 7.

In accordance with the DNV guidelines (DNV, 2012), this study assumed the leak duration equivalent to the total ESD (Emergency Shut Down System) working time of 90 seconds (60 seconds for detection and initiation, 30 seconds for isolation).

The ignition point was assumed to be at the nearest boundaries to the neighbouring modules (Modules 7, 10 and 11) of the module 9 where the impact of VCE to the supporting structures is the most severe. Based on the safety gaps equivalent to the distance from VCE ignition point, $R_{d}$ as used in Eqs (7) and (11), applied to the case vessel, the consequence was translated into the overpressure of explosion at the tolerable frequency (1.0E-3/year). The exceedance diagram of Fig. 6 presents the probability of overpressure generated due to VCE calculated by TNT method. For each case, critical overpressures are determined where tolerable frequency of $1.0 \mathrm{E}-3 /$ year is met.

Table 7 presents the critical overpressures imposed on the supporting structures at the different safety gaps. It highlights the somewhat different results obtained from different empirical methods used for the estimation of overpressure. For Case 1 the overpressure calculated by means of TNO method is relatively higher than others. For Cases 2 and 3 the TNT method produces higher overpressure than others: TNT (0.77 bar), TNO (1.0 bar) and BST (0.7 bar) for Case 1, TNT (1.24 bar), TNO and BST (1.0 bar) for Case 2 while TNT (1.82 bar) and TNO and BST (1.0 bar) for Case 3.

\subsection{Structural safety}

Having calculated the potential impact of VCE, the structural strength of the LNG liquifaciton modules were evaluated using FEA. The FEA model was based on the geometry and material properties 
determined from the current design practices. The material was mild steel having the allowable equivalent stress of $245 \mathrm{~N} / \mathrm{mm}^{2}$ accoring to the rule of DNV Classification (DNV, 2015). The structural foundations consisted of four stools on the hull deck level. The location of the the stools were considered as fixed. In addition, I-beams for horizontal supporting members were used in the design. In FEA, beam elements ('beam 188' in ANSYS) were used to represent the supporting members. Mesh size was 200 $\mathrm{mm}$. I-beam dimensions used in the model is given in Table 8 (DSME, 2013b). Fig. 7 shows the structural model of the LNG liquefaction module.

The thickness of the steel beams was deducted by $1 \mathrm{~mm}$ to account for corrosion based on the rule of DNV Classification (DNV, 2015). Equipment weight was applied to the model as a static load on the top and upper decks, assuming 0.5 tonnes $/ \mathrm{m}^{2}$ as shown in Fig. 8 .

In order to investigate the impact of VCE transient (dynamic) analysis was carried out. Based on a previous research result (Aiwei, 2012), the blast velocity was assumed to be $50 \mathrm{~m} / \mathrm{sec}$ and the triangular pressure load profile was applied as shown in Fig. 9.

In this context, the pressure distributions for TNT model is shown as a function of time in Fig. 10 (a). Total duration was set to be 0.15 seconds ( 3 times of duration of th blast) and maximum pressure value equivelent to the peak overpressures, $\mathrm{P}_{\mathrm{s}}$, obtained from the empirical models. To the next, $10 \%$ of the peak positive phase pressure was applied to the lowest negative phase pressure based on the industrial guidance (Fig. 9) (Aiwei, 2012). Same pressure distributions were applied for TNO and BST models as shown in Fig 10 (b) and (c). Stiffeness proportional damping coefficients $\alpha$ and $\beta$ were assumed to be 0.24572 and 0.000954 based on the actual value of the similar construction module (DSME, 2013a).

Applying different overpressures estimated earlier, the structural strength for the three different cases was evaluated. The explosion pressures are applied to the forward section of the module 11, on the port side elevation of the module 10 and on the aft section of the module 7 and these are denoted as Cases 1, 2 and 3, respectively (Fig. 11). For a worst-case scenario, the blast of VCE was assumed to be impacted in horizontal direction on the web section of the I-beam where the section properties are relatively weak.

Fig. 12 shows the FEA results for the gredients of equivalent stresses imposed on the structures against overpressure estimated by the TNT model, revealing that the maximum equivalent stress imposed on the structure was $526.6 \mathrm{~N} / \mathrm{mm}^{2}$ for Case $1,873.9 \mathrm{~N} / \mathrm{mm}^{2}$ for Case 2 and 1,480.5 N/mm ${ }^{2}$ for Case 3. In all cases the stress far exceeds the tolerable level $\left(245.0 \mathrm{~N} / \mathrm{mm}^{2}\right.$ for mild steel).

Different explosion models, TNO and BST, led to similar results as listed in Table 9. The I-beams are the weakest against the horizontal load. It can be concluded, therefore, that the current design using Ibeams only may not be strong enough. 


\subsection{Safety measures (structural modification)}

In order to improve the structural intergrity against the impact of explosion in horizontal direction, the I-beams were replaced with circular pipes. Table 10 shows the list of pipe dimensions equivelant to Ibeams listed in Table 7. The modified structure was reanalysed for the three cases and these cases were designated as E_Case 1, E_Case 2 and E_Case 3.

The same boundary conditions were used, and the results are illustrated in the Fig. 13. The maximum equivalent stresses on the pipe structure were $219.3 \mathrm{~N} / \mathrm{mm}^{2}$ for E_Case 1, $282.5 \mathrm{~N} / \mathrm{mm}^{2}$ for E_Case 2, 317.1 N/mm² for E_Case 3. The same geometry was modelled using using TNO and BST models for overpressure values and the results are summarised in Table 11.

By replacing the I-beams with equivalent pipe elements, the equivalent stresses are seen to have been reduced by $54 \sim 78 \%$, even though the equivalent stresses are still higher than the allowable stress for safety gaps of $15 \mathrm{~m}$ and less. It can be concluded that pipes are superior to traditional I-beams in this case.

It is worth noting that the area of the structure directly subjected to explosion pressure also determines how much total force is applied to the structure. Therefore, the arrangement of the top-side modules will also contribute to the mitigation of the explosion impact.

Since I-beams are much weaker for the loads on the web than those applied on the flanges (Fig. 14(a)), the direction of the VCE impact is critical. On the other hand, the strength of pipe elements is equally strong for loads from all directions (Fig. 14(b)), and therefore the direction of VCE impact is much less important.

\section{Discussion}

This paper focused on revealing the shortcomings in the current regulatory provisions and practices with regard to the extent of safety gaps in LNG process system on topside of FLNG. In this context, this paper investigated the safety of the system according to rule-makers' standards. For this purpose, too case-specific studies (using designers' approach) may fail to provide a useful insight of general safety. The resulting findings may be subject to questions of general applicability.

To prevent this issue, 'rule-makers approach' (they are always taking conservative stance) deliberately ignores subjective conditions, taking scenario assumptions conservatively to make sure the results are generally applicable to any case rather than a certain case only. 
In this study the magnitude of vapour cloud explosions were estimated using the existing empirical models. It is well understood, however, that the impact of an explosion may be influenced by the site geometry, structures and metrological conditions. Ignoring such factors may lead to over- or underestimation of explosion impact for some cases. If a site-specific micro-scale analysis is to be carried out, the state-of-art methods, such as computational fluid dynamics (CFD), can be used to take into account all these factors. It is believed that the current study, whilst lacking the conditional details, was a valuable exercise as a generic preliminary investigation.

Due to its brevity of history it is far too early to accumulate a meaningful statistics regarding accidents of FLNG. Consequently, this study had to borrow equivalent data from offshore and chemical industries. As a result, there may be some arguments about the accuracy of the estimated frequencies in the quantitative sense. However, there is no doubt whatever that the design of LNG liquefaction module support structures needs to be revisited and it has been made abundantly clear that the safety gaps are indeed very important in ensuring the safety.

Despite some of these shortcomings, this study has given some insight into one aspect of FLNG safety which may benefit ship-owners, designers and rule-makers in their constant endeavour to improve the safety of vessels.

It may be necessary to develop more explosion scenarios and conduct case-by-case simulation by predicting exact leak duration and ignition timing for each case to make it closer to real situations. Since the explosion impact depends on the distance from the ignition point, it is also necessary to study the impact for various points of ignition in conjunction with the probability of ignition taking place at these locations. Furthermore, the structural area which is exposed to the explosion pressure needs to be accurately represented.

Given the fact that this study investigated the adequacy or otherwise of current practices of establishing safety gaps for FLNG topside structures. Consequently, this paper intentionally ignored other types of hazards, such as cryogenic burns, embrittlement, etc., as it is believed they will not influence the extent of the safety gap. On the other hand, this paper is not at all advocating that such hazards are trivial. Indeed, to improve the total safety of FLNGs such hazards will need to be investigated, possibly in future studies.

\section{Concluding remarks}

This study investigated the risk of potential VCE to the structure of liquefaction modules on an FLNG. The results indicate that the magnitude of VCE at a module with a critical probability level is so high that the accident can escalate to the neighbouring modules. It was also found that the extent of the safety 
gaps applied to the case ship may be insufficient in some cases. It was concluded that additional safety measures are required to prevent the accidents from spreading to the neighbouring modules.

Results of FE analysis showed that I-beam structures are vulnerable to the impact of explosion, primarily because such structural elements are non-isotropic with the weakest direction being the horizontal load on the web. It was found that circular pipes of equivalent cross sectional areas can replace the I-beams. Using the pipes as the main structural elements, the safety gaps can be reduced to less than $20 \mathrm{~m}$.

It is believed that it is necessary to establish a more specific regulatory framework urgently so that the safety of these new and potentially popular units can be ensured through better design and construction.

\section{Acknowledgement}

Part of the work described in this paper has been supported by the Korean Government through the scholarship for one of the authors. The authors would like to express their gratitude to the colleagues in Deawoo Shipbuilding \& Marine Engineering co., Ltd (DSME), especially to Mr. Seung-bum Cho for their invaluable support, comments and suggestions. They have contributed considerably to this study.

\section{References}

Alonso, F.D., Ferradás, E.G., Pérez, J.F.S., Aznar, A.M., Gimeno, J.R., Alonso, J.M., 2006. Characteristic overpressure-impulse-distance curves for vapour cloud explosions using the TNO Multi-Energy model. Journal of hazardous materials 137 (2), 734-741.

Bai, Yong. 2016. Chapter 48: Risk and Reliability Applications to FPSO, Marine structural design (second edition). Elsevier, 891-906.

Baker, Q., Tang, M., Scheier, E., Silva, G., 1994. Vapor Cloud Explosion Analysis AIChE Loss Prevention Symposium. Atlanta, Georgia, USA.

Baker, W.E., 1973. Explosions in air. University of Texas Press.

Chae M., 2016. Effect of liquefaciton process selection on explosion risk of LNG-FPSO. Seoul National University.

Crowl, D.A., Louvar, J.F., 2001. Chemical process safety: fundamentals with applications. Pearson Education. 
Czujko, J., Paik, J.K., 2015. A new method for accidental limit states design of thin-walled structures subjected to hydrocarbon explosion loads. Ships and Offshore Structures 10 (5), 460-469.

Dan, et al., 2014. Quantitative risk analysis of fire and explosion on the top-side LNG-liquefaction process of LNG-FPSO. Process Safety and Environmental Protection 92, 430-441.

DSME, 2013a, Dynamic structure response analysis procedure for over pressure on topside structure in explosion situation, Ref. No DSE-201310-0052.

DSME, 2013b, Structural drawing - topsides module 1107.

DNV, 2012. failure frequency guidance: Process Equipment Leak Frequency Data for use in QRA, Oslo Norway.

DNV, 2015. DNV Rules for Classification of Ships, Part 3 Chapter 1 Hull structural design - Ships with length 100 metres and above.

Eslami-Majd, A., Rahbar-Ranji, A., 2015. Deformation behaviour of corroded plates subjected to blast loading. Ships and Offshore Structures 10 (1), 79-93.

Faber, M.H., Straub, D., Heredia-Zavoni, E., Montes-Iturrizaga, R., 2012. Risk assessment for structural design criteria of FPSO systems. Part I: Generic models and acceptance criteria. Marine Structures 28 (1), 120-133.

Heredia-Zavoni, E., Montes-Iturrizaga, R., Faber, M.H., Straub, D., 2012. Risk assessment for structural design criteria of FPSO systems. Part II: Consequence models and applications to determination of target reliabilities. Marine Structures 28 (1), 50-66.

Holden, D., 2014. Liquefied Natural Gas (LNG) Bunkering Study (No. PP087423-4, Rev 3).

IGU, 2015. IGU World LNG Report - 2015 Edition. World Gas Conference Edition, Fornebu, Norway. IMO, 2002. MSC/Circ.1023, MEPC/Circ.392: Guidelines for Formal Safety Assessment (FSA) for Use in the IMO Rule-making Process, in: IMO (Ed.), London, UK.

Jeong, B., Lee B., Zhou P., Ha S., 2016. Quantitative Risk Assessment of Medium-Sized Floating Regasification Unit using System Hierarchical modelling, Journal of Ocean Engineering (Under Review).

Jin, Y., Jang, B.-S., 2015. Probabilistic fire risk analysis and structural safety assessment of FPSO topside module. Ocean Engineering 104, 725-737. 
Lee, J.-C., Cha, J.-H., Roh, M.-I., Hwang, J.-H., Lee, K.-Y., 2012. Determination of the optimal operating condition of dual mixed refrigerant cycle of LNG FPSO topside liquefaction process. Journal of the Society of Naval Architects of Korea 49 (1), 33-44.

Li, J., Ma, G., Abdel-jawad, M., Huang, Y., 2016. Gas dispersion risk analysis of safety gap effect on the innovating FLNG vessel with a cylindrical platform. Journal of Loss Prevention in the process industries 40, 304-316.

NORSOK, 2001. Standard Z-013 - Risk and emergency preparedness analysis. NORSOK, Norway. OGP, 2010. Risk Assessment Data Directory, Ignition probabilities, London, UK.

Paik, J.K., Czujko, J., 2011. Assessment of hydrocarbon explosion and fire risks in offshore installations: recent advances and future trends. The IES Journal Part A: Civil \& Structural Engineering 4 (3), 167 179.

Paik, J., Czujko, J., Kim, S., Lee, J., Kim, B., Seo, J., Ha, Y., 2014. A new procedure for the nonlinear structural response analysis of offshore installations in explosions, SNAME Maritime Convention; October, pp. 22-24.

Paik, J., Kim, B., Jeong, J., Kim, S., Jang, Y., Kim, G., Woo, J., Kim, Y., Chun, M., Shin, Y., 2010. CFD simulations of gas explosion and fire actions. Ships and Offshore Structures 5 (1), 3-12.

Sohn, J.M., Kim, S.J., Kim, B.H., Paik, J.K., 2013. Nonlinear structural consequence analysis of FPSO topside blastwalls. Ocean Engineering 60, 149-162.

Sohn, J.M., Kim, S.J., Seo, J.K., Kim, B.J., Paik, J.K., 2016. Strength assessment of stiffened blast walls in offshore installations under explosions. Ships and Offshore Structures 11 (5), 551-560.

Spouge, J., 1999. A guide to quantitative risk assessment for offshore installations. CMPT Aberdeen, SD.

Su, A., 2012. Analysis of Explosion Load Effects in Pipe-racks: Explosion simulation and its respective structural response on pipe-racks on a offshore topside module.

Vinnem, J.E., 2007. Offshore Risk Assessment Principles, Modeling and Applications of QRA studies. Springer, London.

Woodward, J.L., Pitbaldo, R., 2010. LNG Risk Based Safety: modeling and consequence analysis. John Wiley \& Sons. 
Yoon, J., Ha J. and Park J, 2008. LNG vapour dispersion from atmospheric relief valve, International gas union research conference, Paris. 


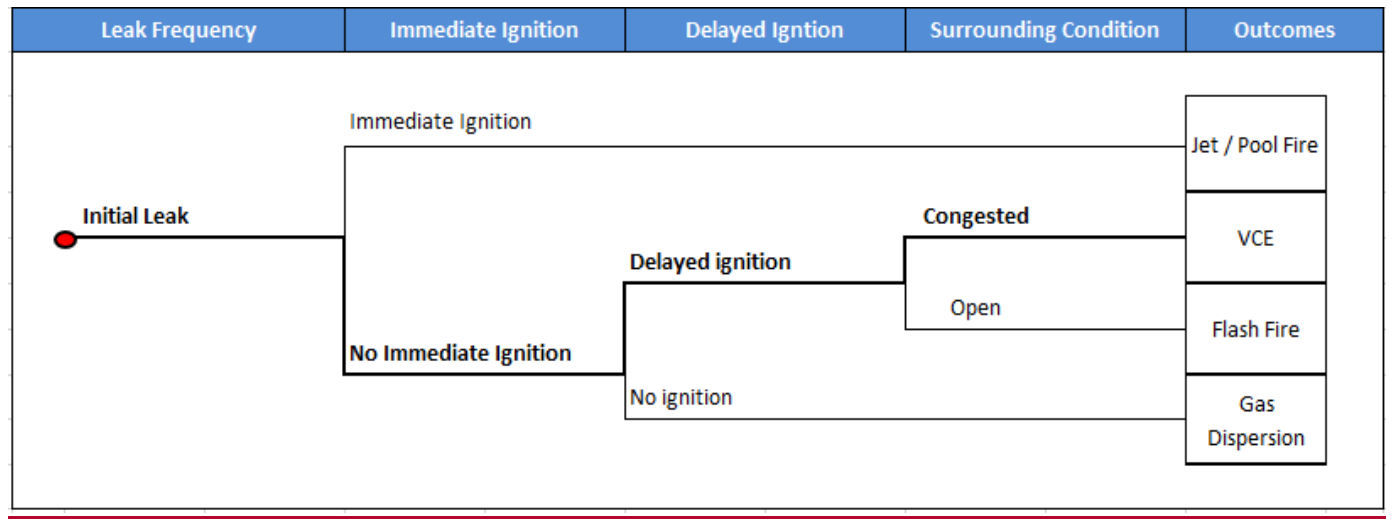

Fig. 1. Proposed event tree (Dan et al, 2014; Woodward, 2010). 


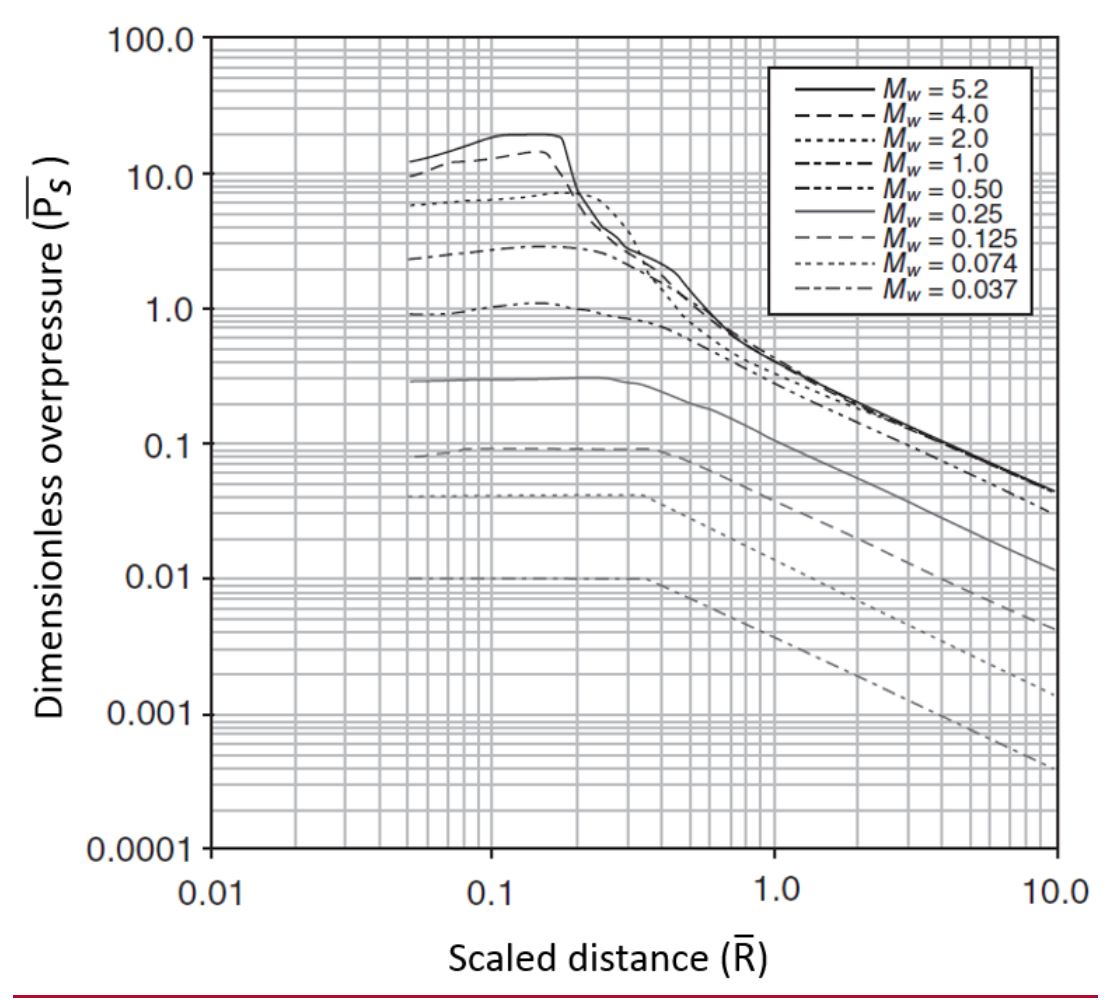

Fig. 2. Dimensionless peak overpressure vs scaled distance for BST model (Melton and Marx, 2009; Woodward and Pitbaldo, 2010). 


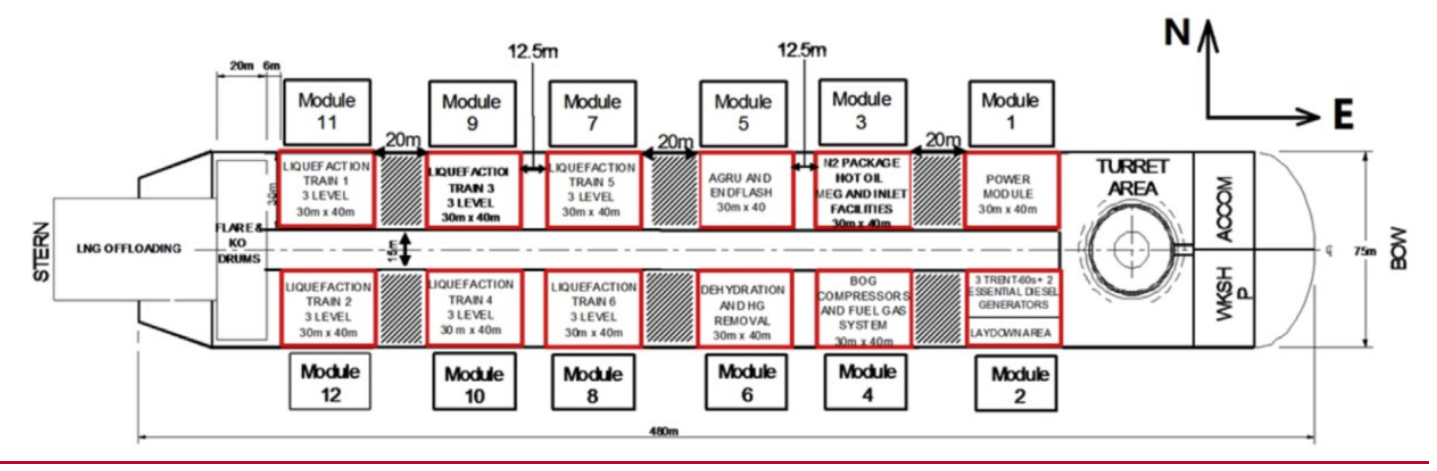

Fig. 3. Top side arrangement of FLNG (Lee et al., 2016). 


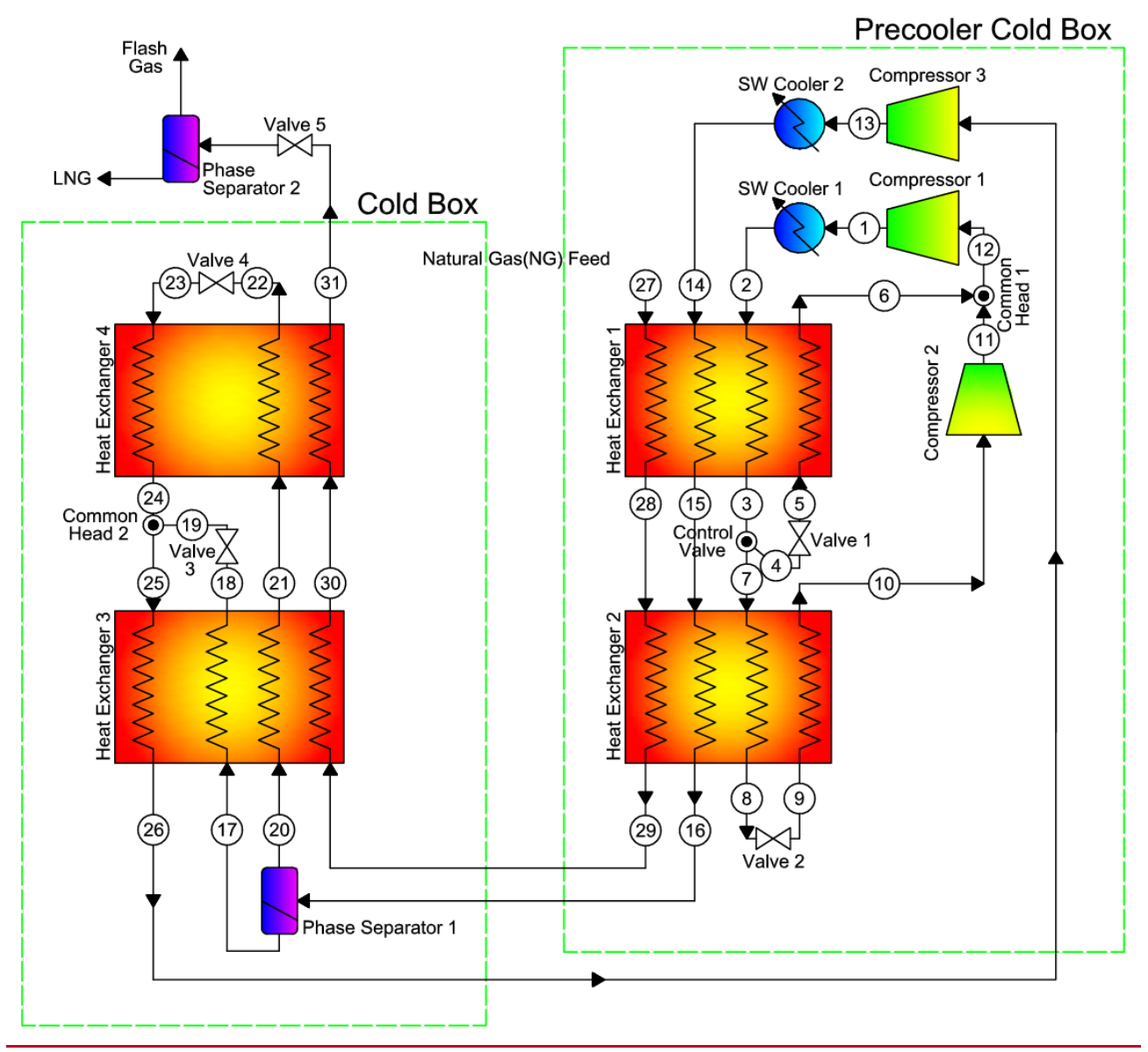

Fig. 4. Configuration of liquefaction process system (Lee et al., 2012). 


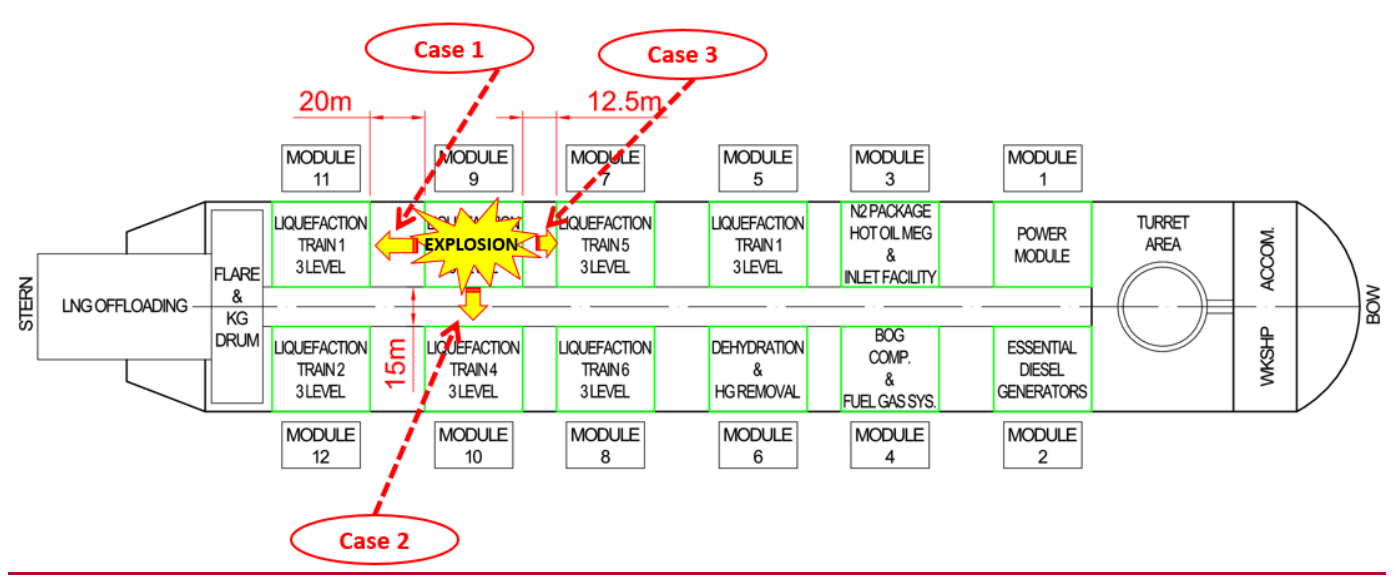

Fig. 5. Top-side arrangement of the modules. 


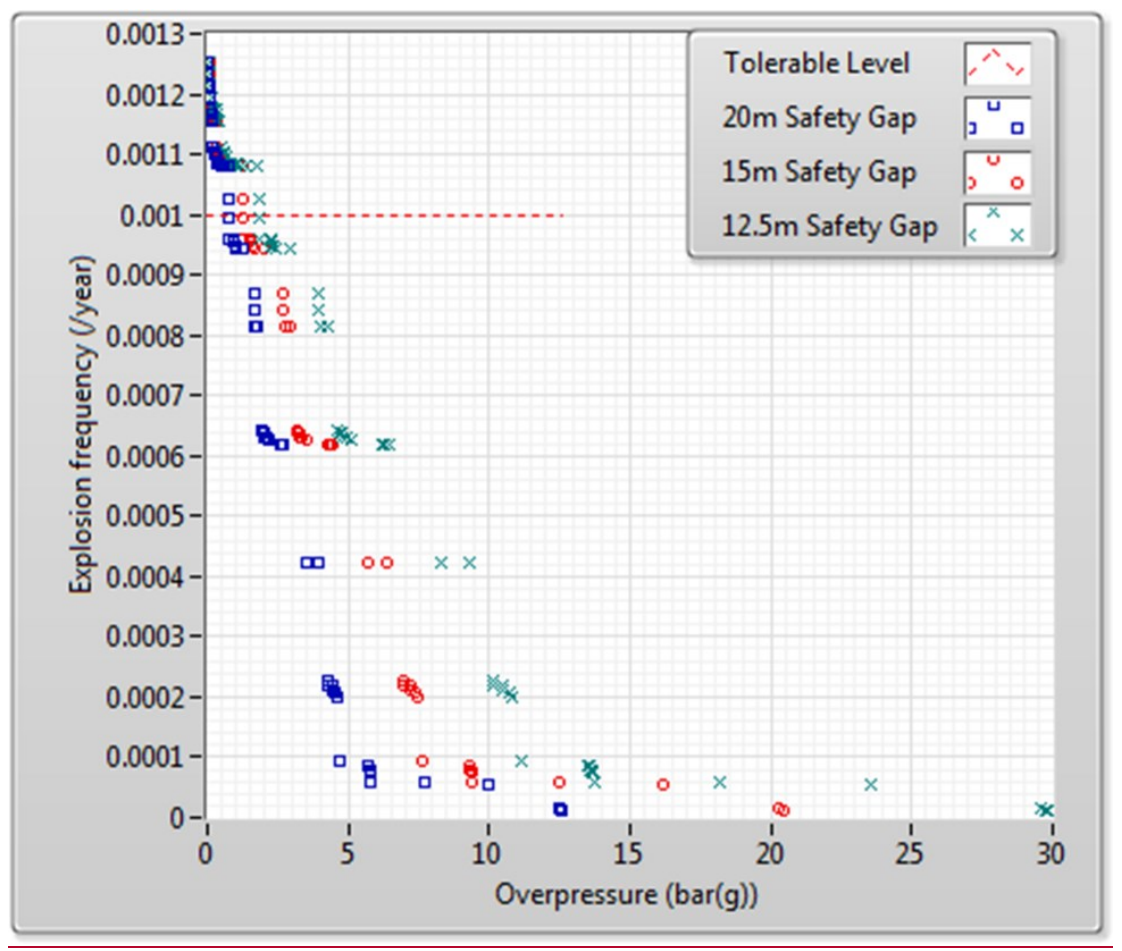

Fig. 6. Exceedance diagram for overpressure with respect to explosion frequency (TNT method). 


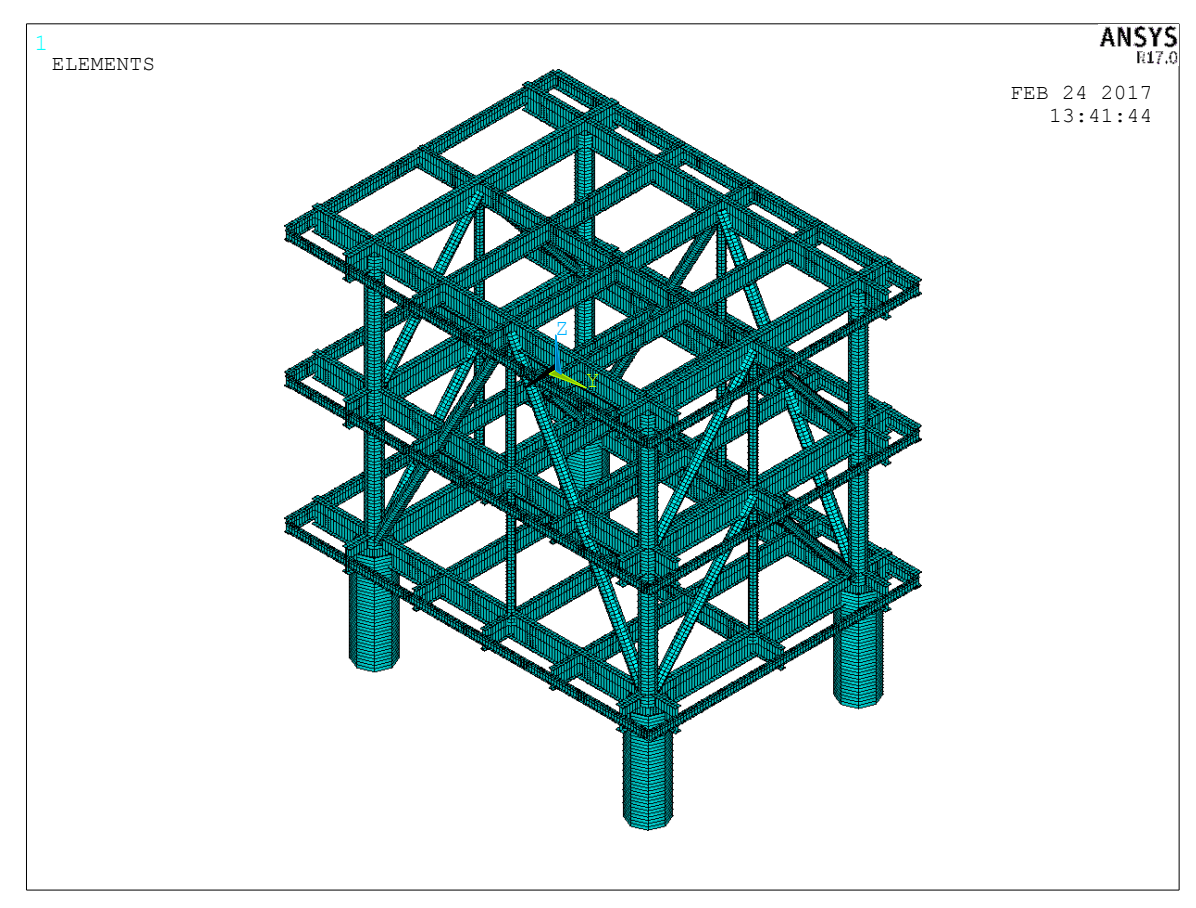

Fig. 7. Structural model of the LNG liquefaction module. 


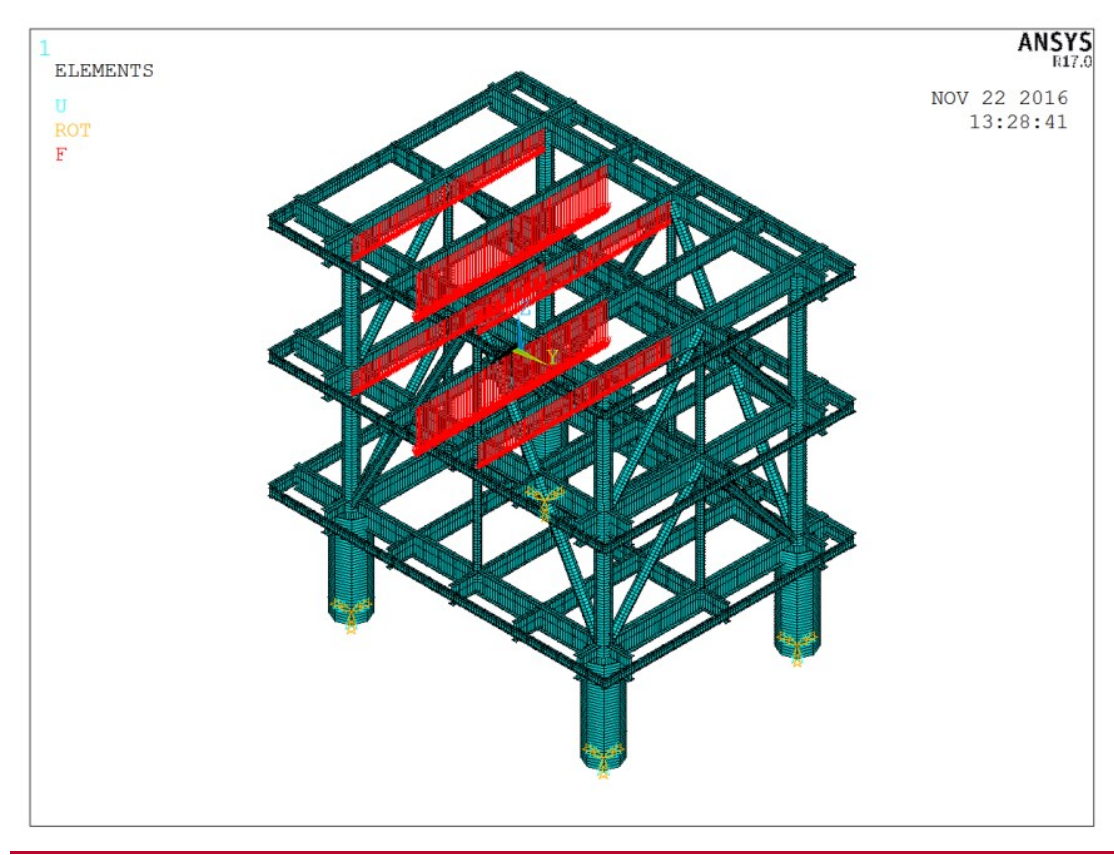

Fig. 8. Applied static load considering equipment weight 


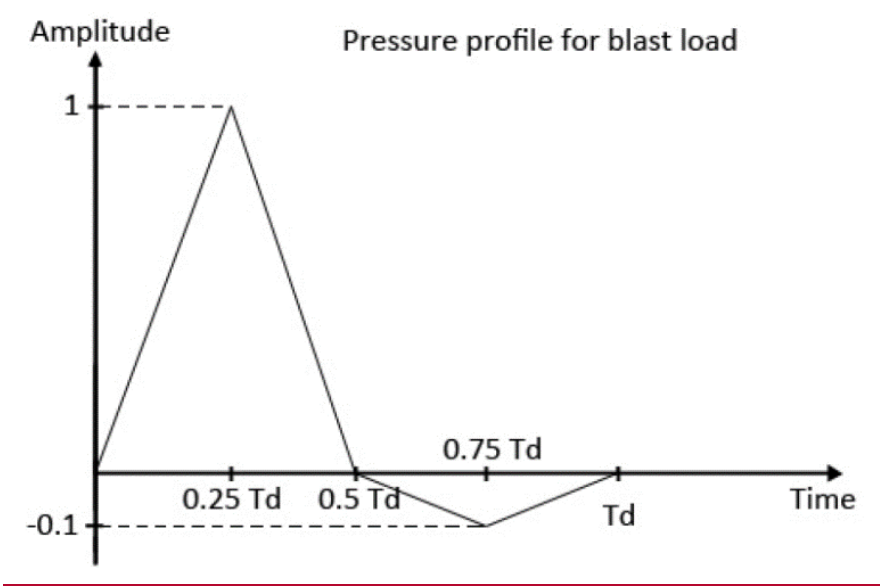

Fig. 9. Triangular blast pressure profile (Aiwei, 2012). 


\section{(a) TNT method}

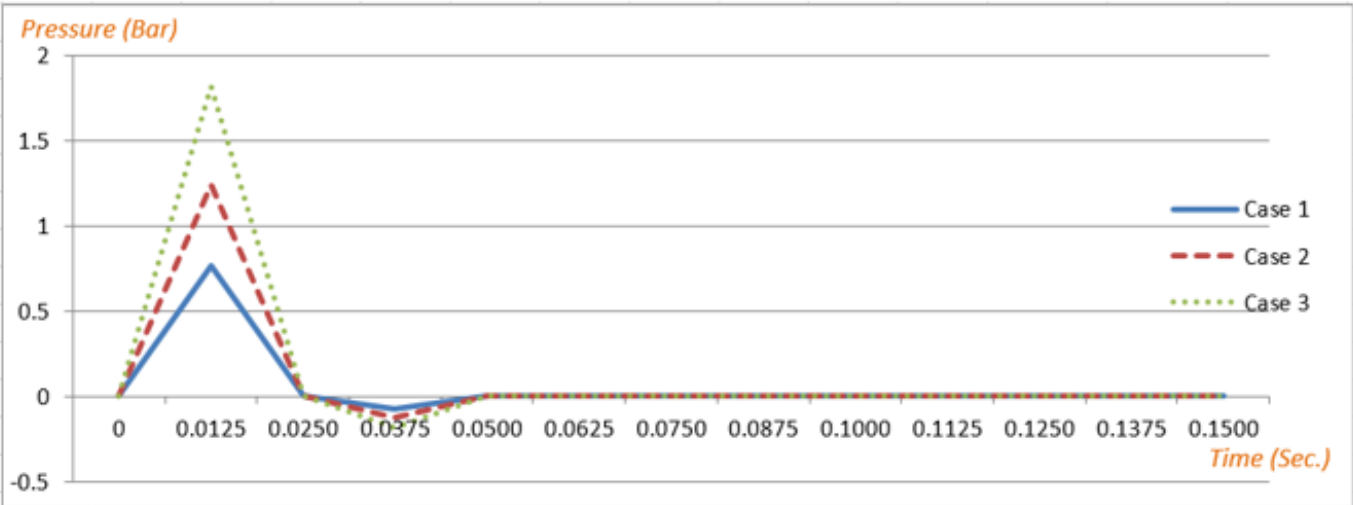

\section{(b) TNO method}

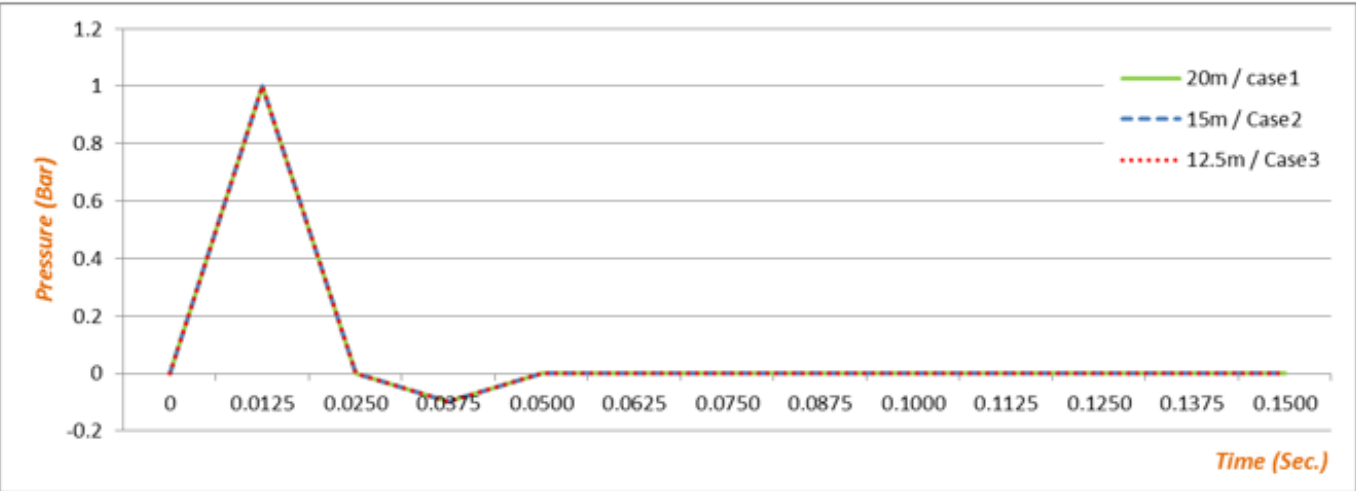

\section{(c) BST method}

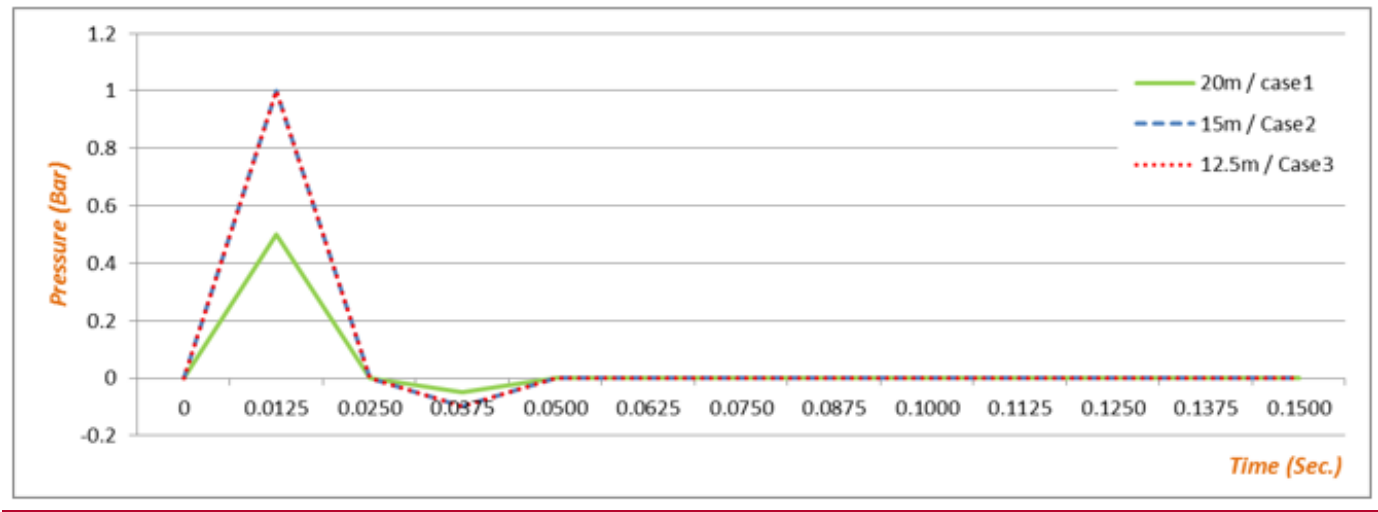

Fig. 10. Pressure-time curve 


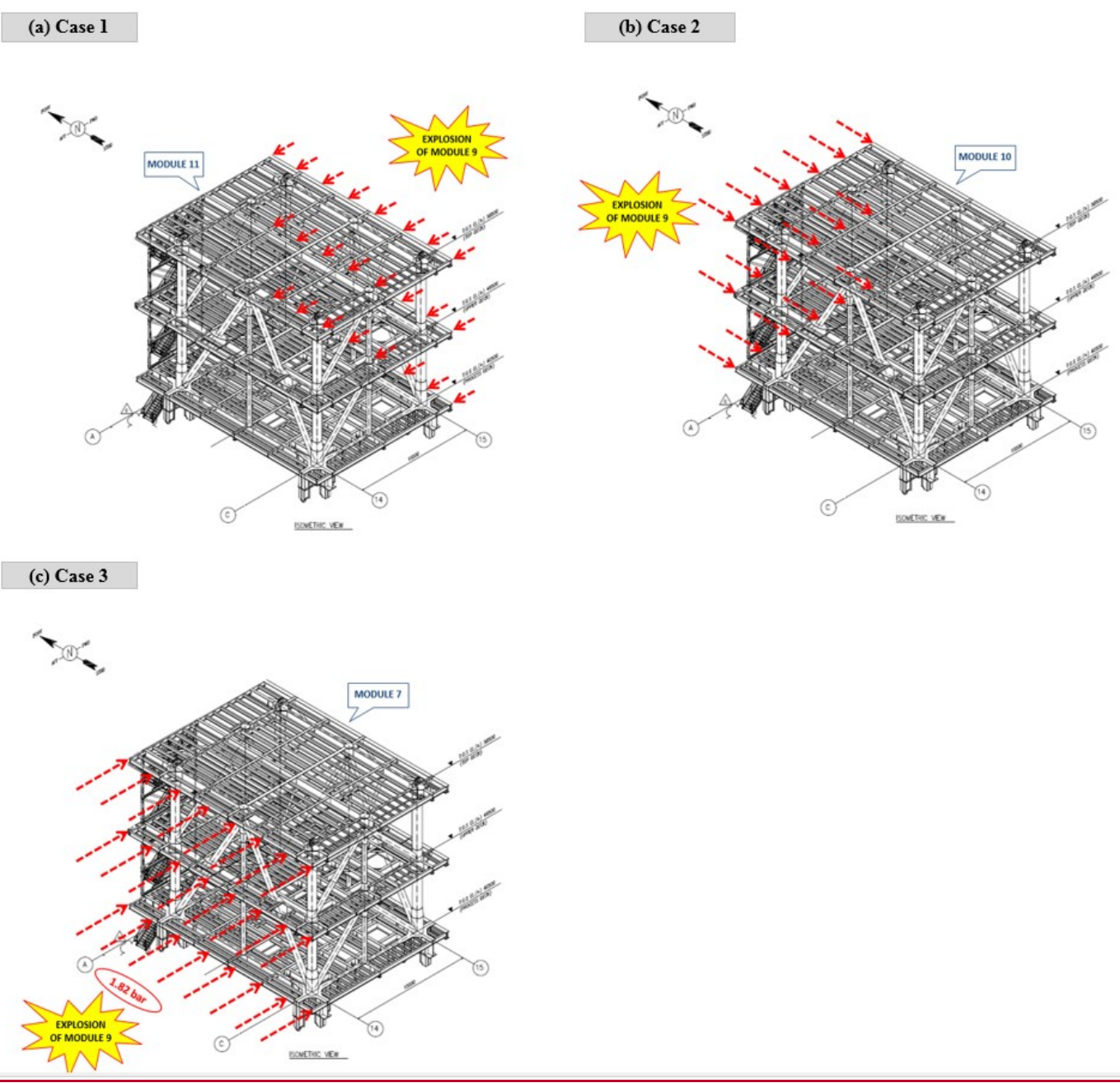

Fig. 11. VCE Cases 
(a) Case $1 \quad$ (20m dist. $/ 0.77 \mathrm{bar} / 0.075 \mathrm{Sec}$.)

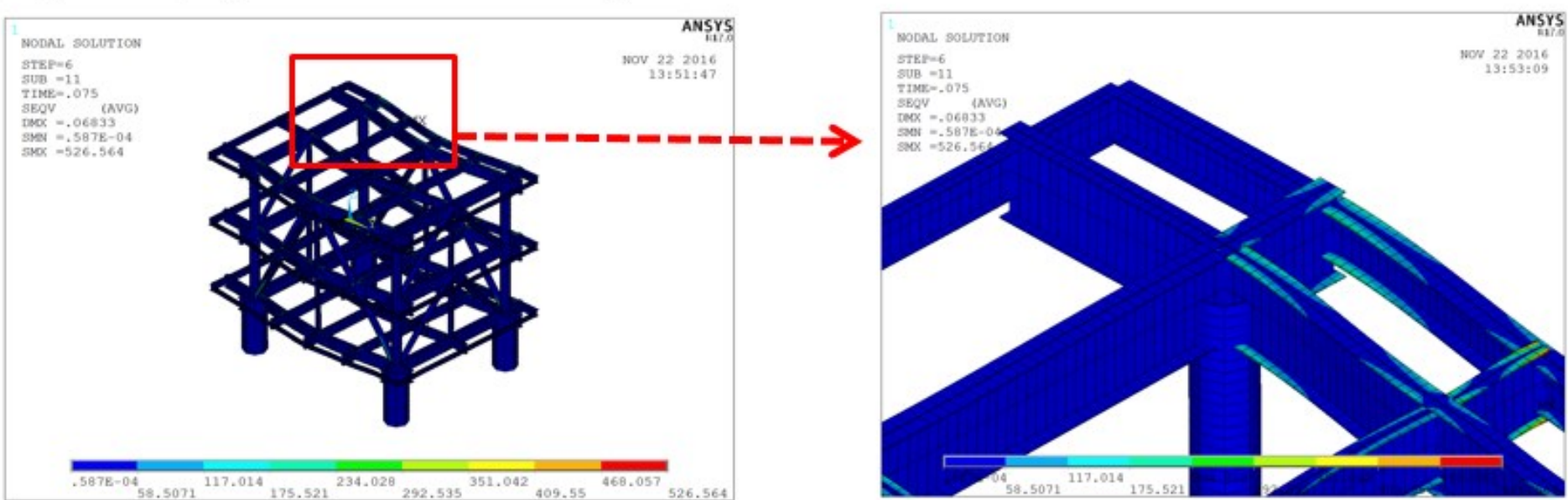

(b) Case 2 (15m dist $/ 1.24 \mathrm{bar} / 0.0375 \mathrm{Sec}$.)
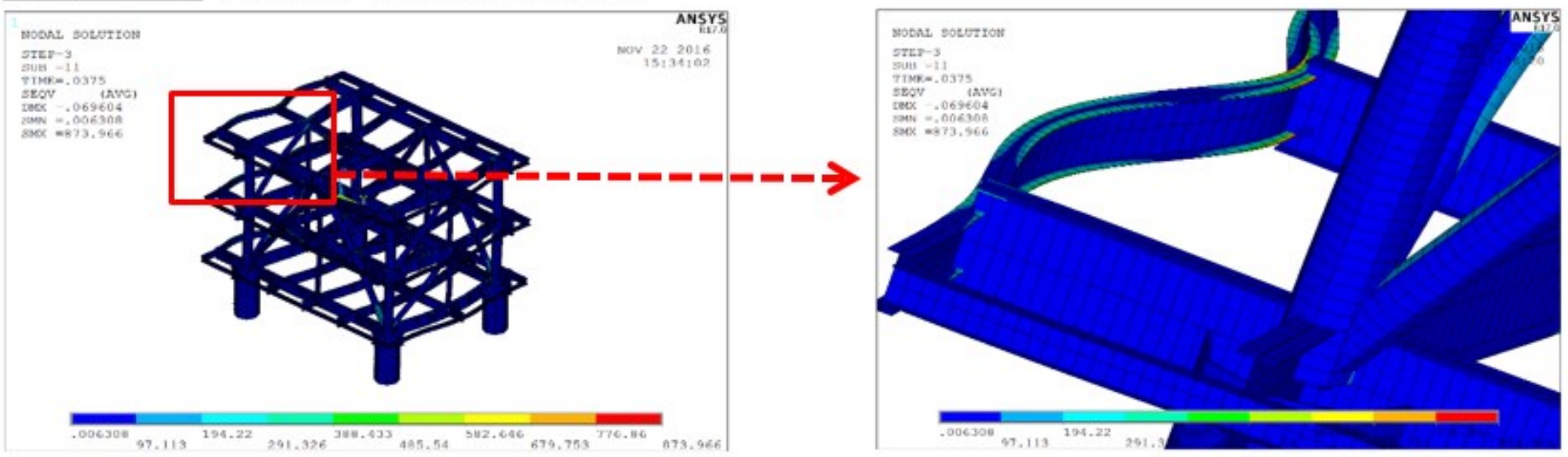

\section{(c) Case 3 (12.5m dist $/ 1.82 \mathrm{bar} / 0.0125 \mathrm{sec}$.)}
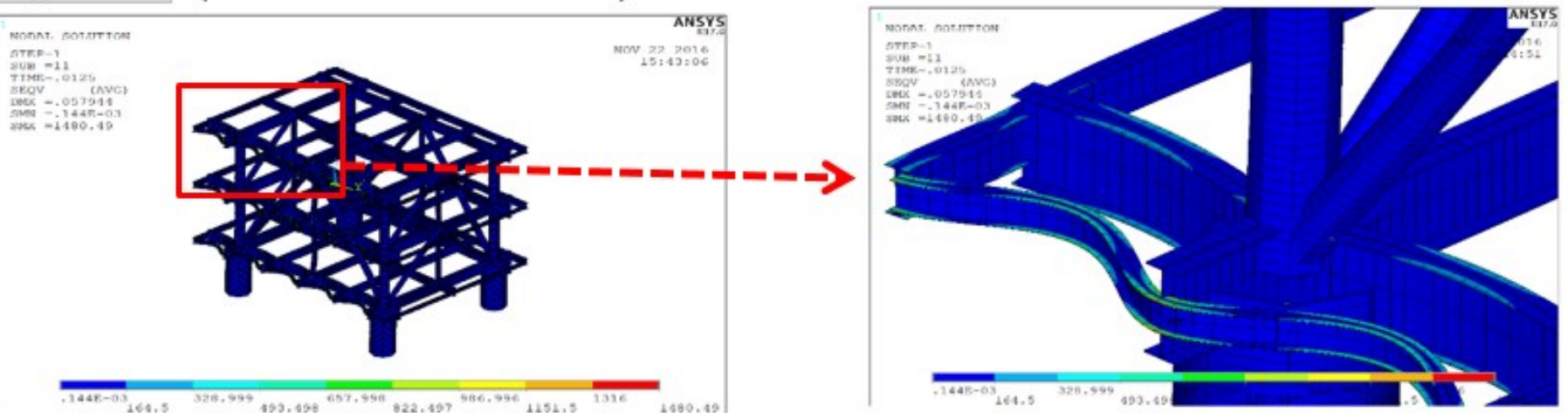

Fig. 12. Results of FEA based on the TNT method. 
(a) E_Case 1 (20m dist./ 0.77bar/ 0.05Sec.)

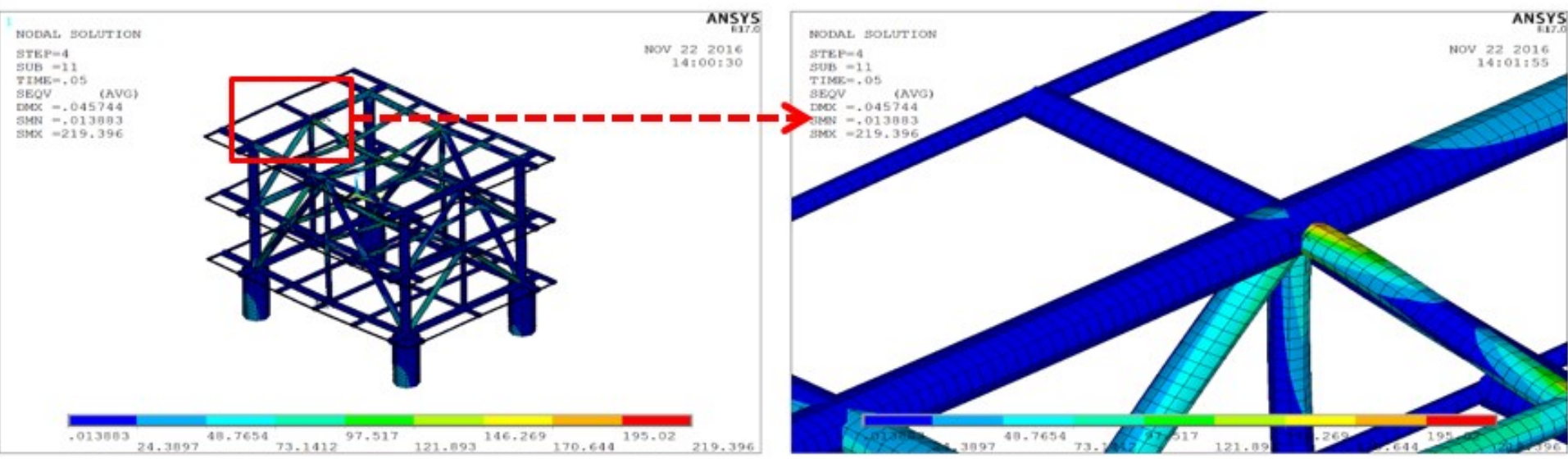

(b) E_Case 2 (15m dist. $/ 1.24 \mathrm{bar} / 0.05 \mathrm{Sec}$. $)$
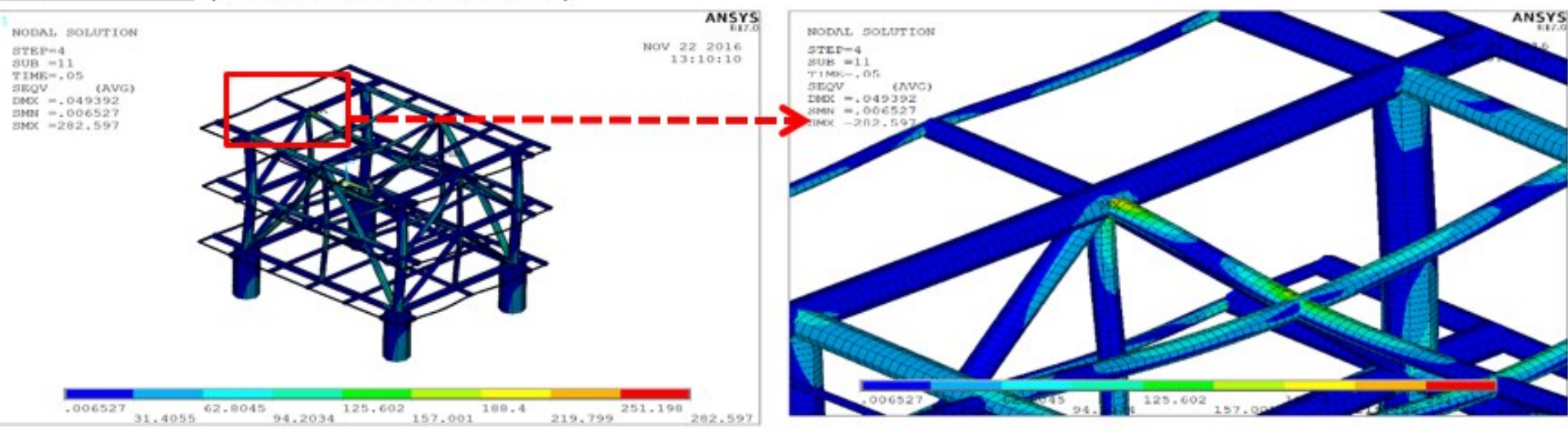

(c) E_Case 3 (12.5m dist $/ 1.82 \mathrm{bar} / 0.0125 \mathrm{sec}$. $)$

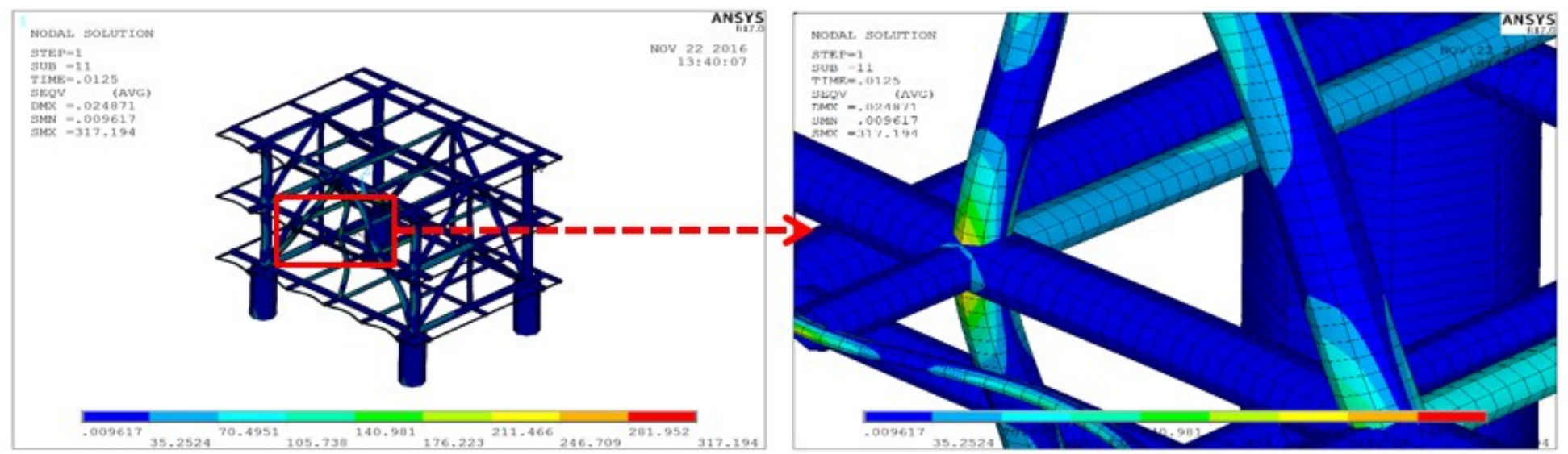

Fig. 13. Results of FE analysis on modified structure for the TNT model. 
(a) I-beam member

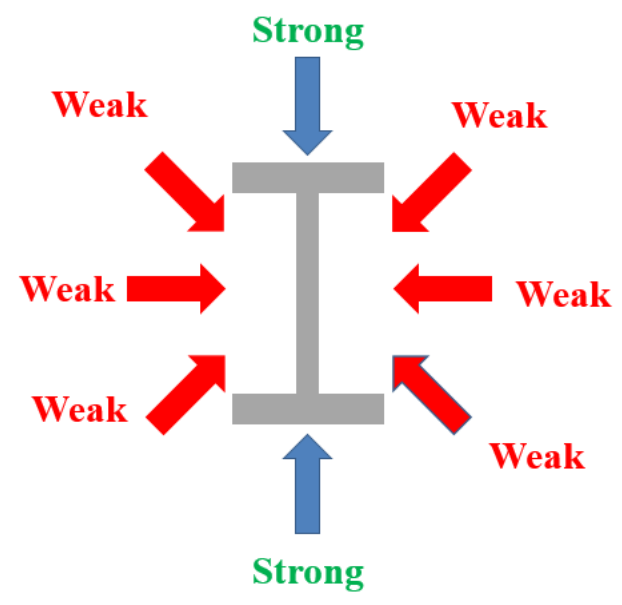

(b) Pipe member

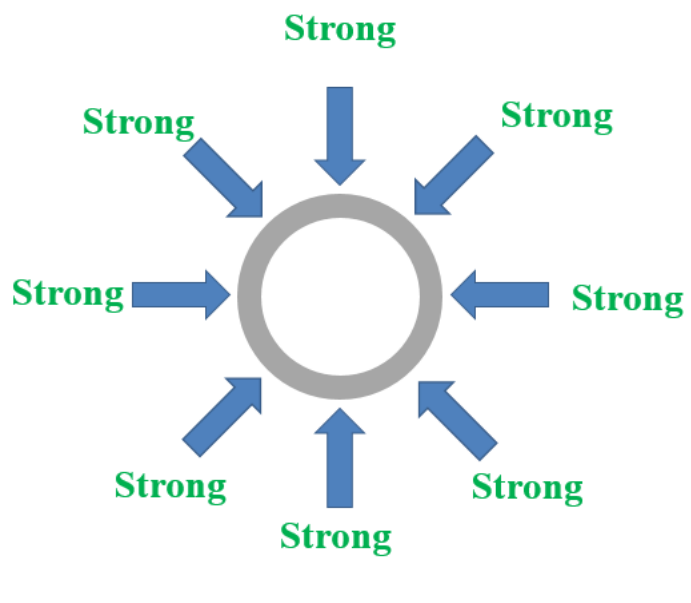

Fig. 14. Directionality of structural strength of I-beams and round pipes 
Table 1 Probability of immediate ignition (DNV, 2012).

\begin{tabular}{|c|c|c|}
\hline \multicolumn{2}{|c|}{ Release rate $(\mathrm{kg} / \mathrm{s})$} & $\frac{\text { Immediate ignition }}{\text { probability }}$ \\
\hline$\underline{\text { Gas }}$ & $\underline{\text { Liquid }}$ & $\underline{ }$ \\
\hline$\leq 1$ & $\underline{<1.2}$ & $\underline{0.01 \%}$ \\
\hline$\underline{1-10}$ & $\underline{1.2-25}$ & $\underline{0.1 \%}$ \\
\hline$\underline{10}$ & $\underline{25}$ & $\underline{1 \%}$ \\
\hline
\end{tabular}


Table 2 Probability of delayed ignition (OGP, 2010).

\begin{tabular}{|c|c|c|}
\hline \multirow{2}{*}{$\begin{array}{c}\text { Release } \\
\text { rate(kg/s) }\end{array}$} & \multicolumn{2}{|c|}{ Delayed ignition probability } \\
\hline & Offshore FPSO gas & $\underline{\text { Offshore FPSO liquid }}$ \\
\hline$\underline{0.1}$ & $\underline{0.001}$ & $\underline{0.001}$ \\
\hline$\underline{0.2}$ & $\underline{0.0011}$ & $\underline{0.0014}$ \\
\hline$\underline{0.5}$ & $\underline{0.0012}$ & $\underline{0.0022}$ \\
\hline$\underline{1.0}$ & $\underline{0.0013}$ & $\underline{0.003}$ \\
\hline$\underline{2.0}$ & $\underline{0.003}$ & $\underline{0.0042}$ \\
\hline$\underline{5.0}$ & $\underline{0.0092}$ & $\underline{0.0066}$ \\
\hline$\underline{10.0}$ & $\underline{0.0213}$ & $\underline{0.0092}$ \\
\hline$\underline{20.0}$ & $\underline{0.0493}$ & $\underline{0.0129}$ \\
\hline$\underline{50.0}$ & $\underline{0.15}$ & $\underline{0.02}$ \\
\hline$\underline{100.0}$ & $\underline{0.15}$ & $\underline{0.028}$ \\
\hline$\underline{200.0}$ & $\underline{0.15}$ & $\underline{0.028}$ \\
\hline$\underline{500.0}$ & $\underline{0.15}$ & $\underline{0.028}$ \\
\hline$\underline{1000.0}$ & $\underline{0.15}$ & $\underline{0.028}$ \\
\hline
\end{tabular}


$\underline{\text { Table } 3 \text { Mach numbers (Mw) for BST model }}$

(Melton and Marx, 2009; Woodward and Pitbaldo, 2010).

\begin{tabular}{|c|c|c|c|c|}
\hline \multirow{2}{*}{$\begin{array}{c}\text { Flame } \\
\text { Expansion }\end{array}$} & \multirow{2}{*}{\begin{tabular}{c}
\multicolumn{1}{r}{ Fuel } \\
$\underline{\text { Reactivity }}$
\end{tabular}} & \multicolumn{3}{|c|}{ Obstacle Density } \\
\hline & & Low & Medium & $\underline{\text { High }}$ \\
\hline \multirow[t]{3}{*}{$\underline{1 \mathrm{D}}$} & $\underline{\text { High }}$ & $\underline{5.2}$ & $\underline{5.2}$ & $\underline{5.2}$ \\
\hline & Medium & $\underline{1.03}$ & $\underline{1.77}$ & $\underline{2.27}$ \\
\hline & Low & $\underline{0.294}$ & 1.03 & 2.27 \\
\hline \multirow[t]{3}{*}{$\underline{2 \mathrm{D}}$} & $\underline{\text { High }}$ & $\underline{0.59}$ & $\underline{1.03}$ & $\underline{1.77}$ \\
\hline & $\underline{\text { Medium }}$ & $\underline{0.47}$ & $\underline{0.66}$ & $\underline{1.6}$ \\
\hline & $\underline{\text { Low }}$ & $\underline{0.079}$ & $\underline{0.47}$ & $\underline{0.66}$ \\
\hline \multirow[t]{3}{*}{$\underline{2.5 \mathrm{D}}$} & $\underline{\text { High }}$ & $\underline{0.47}$ & $\underline{0.58}$ & $\underline{1.18}$ \\
\hline & $\underline{\text { Medium }}$ & $\underline{0.29}$ & $\underline{0.55}$ & $\underline{1.0}$ \\
\hline & $\underline{\text { Low }}$ & $\underline{0.053}$ & $\underline{0.35}$ & $\underline{0.5}$ \\
\hline \multirow[t]{3}{*}{$\underline{3 \mathrm{D}}$} & $\underline{\text { High }}$ & $\underline{0.36}$ & $\underline{0.153}$ & $\underline{0.588}$ \\
\hline & Medium & $\underline{0.11}$ & $\underline{0.44}$ & $\underline{0.5}$ \\
\hline & $\underline{\text { Low }}$ & $\underline{0.026}$ & $\underline{0.23}$ & $\underline{0.34}$ \\
\hline
\end{tabular}


Table 4 System characteristics of each group (Lee et al., 2012).

\begin{tabular}{|c|c|c|c|c|c|c|c|c|c|c|c|c|c|c|c|c|}
\hline \multirow[b]{2}{*}{$\frac{\text { Group }}{\underline{\text { No. }}}$} & \multicolumn{3}{|c|}{$\underline{\text { Operation conditions }}$} & \multicolumn{7}{|c|}{ Mass Composition (\%) } & \multicolumn{6}{|c|}{ Equipment list (number of items) } \\
\hline & $\begin{array}{l}\text { Press. } \\
\text { (bar) }\end{array}$ & $\begin{array}{l}\text { Temp. } \\
\underline{(\mathrm{K})}\end{array}$ & Phase & Ethane & Propane & $\underline{\text { nButane }}$ & $\frac{\text { Nitro- }}{\text { gen }}$ & Methane & $\underline{\text { iButane }}$ & iPentane & $\begin{array}{c}\text { Compre- } \\
\text { ssor }\end{array}$ & $\underline{\text { Flange }}$ & $\begin{array}{c}\frac{\text { Heat }}{\text { exchanger }} \\
\underline{\text { nat }}\end{array}$ & $\begin{array}{l}\text { Pipe } \\
\text { (per } \\
\text { meter) }\end{array}$ & $\underline{\text { Trap }}$ & $\begin{array}{l}\text { Exp. } \\
\text { valve }\end{array}$ \\
\hline$\underline{1}$ & $\underline{19.2}$ & $\underline{353.5}$ & $\underline{\mathrm{V}}$ & $\underline{24.82}$ & $\underline{64.16}$ & $\underline{11.02}$ & 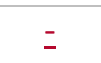 & $\overline{-}$ & $=$ & $=$ & $\underline{1}$ & $\underline{2}$ & $\overline{-}$ & $\underline{1}$ & $=$ & $=$ \\
\hline$\underline{2}$ & $\underline{19.2}$ & $\underline{309.5}$ & $\underline{L}$ & $\underline{24.82}$ & $\underline{64.16}$ & $\underline{11.02}$ & 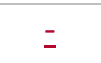 & $\bar{z}$ & $=$ & $=$ & $=$ & $\underline{2}$ & $\underline{1}$ & $\underline{1}$ & $=$ & $=$ \\
\hline$\underline{3}$ & $\underline{19.2}$ & $\underline{273.1}$ & $\underline{L}$ & $\underline{24.82}$ & $\underline{64.16}$ & $\underline{11.02}$ & $=$ & $\bar{z}$ & $\bar{z}$ & $=$ & $=$ & $\underline{2}$ & $\underline{1}$ & $\underline{1}$ & $=$ & $=$ \\
\hline$\underline{4}$ & $\underline{19.2}$ & $\underline{273.1}$ & $\underline{L}$ & $\underline{24.82}$ & $\underline{64.16}$ & $\underline{11.02}$ & $=$ & $=$ & $=$ & $=$ & $\underline{1}$ & $\underline{2}$ & $=$ & $\underline{1}$ & $=$ & $=$ \\
\hline$\underline{5}$ & $\underline{7.6}$ & $\underline{270.0}$ & $\underline{L}$ & $\underline{24.82}$ & $\underline{64.16}$ & $\underline{11.02}$ & $=$ & $=$ & $\bar{z}$ & $=$ & $=$ & $\underline{2}$ & $=$ & $\underline{1}$ & $=$ & $\underline{1}$ \\
\hline$\underline{6}$ & $\underline{7.6}$ & $\underline{302.1}$ & $\underline{\mathrm{V}}$ & $\underline{24.82}$ & $\underline{64.16}$ & $\underline{11.02}$ & $=$ & $\bar{z}$ & $\bar{z}$ & $=$ & $=$ & $\underline{2}$ & $\underline{1}$ & $\underline{1}$ & $=$ & $z$ \\
\hline$\underline{7}$ & $\underline{19.2}$ & $\underline{273.0}$ & $\underline{L}$ & $\underline{24.82}$ & $\underline{64.16}$ & $\underline{11.02}$ & $\Xi$ & 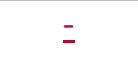 & 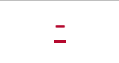 & $\Xi$ & $\Xi$ & $\underline{2}$ & $\overline{-}$ & $\underline{1}$ & $=$ & $=$ \\
\hline 8 & $\underline{19.2}$ & $\underline{240.0}$ & $\underline{L}$ & $\underline{24.82}$ & $\underline{64.16}$ & $\underline{11.02}$ & $=$ & $=$ & $\bar{z}$ & $=$ & $=$ & $\underline{2}$ & $\underline{1}$ & $\underline{1}$ & $=$ & $\bar{z}$ \\
\hline$\underline{9}$ & $\underline{2.8}$ & $\underline{236.5}$ & $\underline{L}$ & $\underline{24.82}$ & $\underline{64.16}$ & $\underline{11.02}$ & $=$ & $=$ & $=$ & $=$ & $=$ & $\underline{2}$ & $=$ & $\underline{1}$ & $=$ & $\underline{1}$ \\
\hline$\underline{10}$ & $\underline{2.8}$ & $\underline{267.8}$ & $\underline{\mathrm{V}}$ & $\underline{24.82}$ & $\underline{64.16}$ & $\underline{11.02}$ & $=$ & $=$ & $\bar{z}$ & $=$ & $=$ & $\underline{2}$ & $\underline{1}$ & $\underline{1}$ & $=$ & $=$ \\
\hline 11 & $\underline{7.6}$ & $\underline{312.6}$ & $\underline{\mathrm{V}}$ & $\underline{24.82}$ & $\underline{64.16}$ & $\underline{11.02}$ & $=$ & $=$ & $=$ & $=$ & $\underline{1}$ & $\underline{2}$ & $=$ & $\underline{1}$ & $=$ & $=$ \\
\hline$\underline{12}$ & $\underline{7.6}$ & $\underline{307.2}$ & $\underline{\mathrm{V}}$ & $\underline{24.82}$ & $\underline{64.16}$ & $\underline{11.02}$ & $=$ & $\bar{z}$ & z & z & $=$ & $\underline{2}$ & $=$ & $\underline{1}$ & $=$ & $=$ \\
\hline$\underline{13}$ & $\underline{48.6}$ & $\underline{414.9}$ & $\underline{\mathrm{V}}$ & $\underline{29.9}$ & $\underline{21.3}$ & $=$ & $\underline{7}$ & $\underline{41.8}$ & 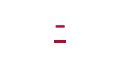 & $=$ & $\underline{1}$ & $\underline{2}$ & $=$ & $\underline{1}$ & $=$ & $=$ \\
\hline$\underline{14}$ & $\underline{48.6}$ & $\underline{305.0}$ & $\underline{\mathrm{V}}$ & $\underline{29.9}$ & $\underline{21.3}$ & $\overline{-}$ & $\underline{7}$ & $\underline{41.8}$ & $\bar{z}$ & $=$ & $=$ & $\underline{2}$ & $\underline{1}$ & 1 & $=$ & $=$ \\
\hline$\underline{15}$ & $\underline{48.6}$ & $\underline{273.1}$ & $\underline{\mathrm{V}}$ & $\underline{29.9}$ & $\underline{21.3}$ & $=$ & $\underline{7}$ & $\underline{41.8}$ & $=$ & $=$ & $=$ & $\underline{2}$ & $\underline{1}$ & $\underline{1}$ & $=$ & $=$ \\
\hline$\underline{16}$ & $\underline{48.6}$ & $\underline{240.0}$ & $\underline{L}$ & $\underline{29.9}$ & $\underline{21.3}$ & $=$ & $\underline{7}$ & $\underline{41.8}$ & $=$ & $=$ & $=$ & $\underline{2}$ & $\underline{1}$ & $\underline{1}$ & $=$ & $=$ \\
\hline$\underline{17}$ & $\underline{48.6}$ & $\underline{240.0}$ & $\underline{L}$ & $\underline{35.0}$ & $\underline{30.1}$ & $=$ & $\underline{2.9}$ & $\underline{32}$ & $=$ & $=$ & $=$ & $\underline{2}$ & $=$ & $\underline{1}$ & $\underline{1}$ & $=$ \\
\hline$\underline{18}$ & $\underline{48.6}$ & $\underline{144.7}$ & $\underline{L}$ & $\underline{35.0}$ & $\underline{30.1}$ & $=$ & $\underline{2.9}$ & $\underline{32}$ & $=$ & $=$ & $=$ & $\underline{2}$ & $\underline{1}$ & $\underline{1}$ & $=$ & $=$ \\
\hline
\end{tabular}




\begin{tabular}{|l|c|c|c|c|c|c|c|c|c|c|c|c|c|c|c|c|}
\hline$\underline{19}$ & $\underline{3}$ & $\underline{139.2}$ & $\underline{\underline{2}}$ & $\underline{35.0}$ & $\underline{30.1}$ & $=$ & $\underline{2.9}$ & $\underline{32}$ & $=$ & $=$ & $=$ & $\underline{2}$ & $=$ & $\underline{1}$ & $=$ & $\underline{1}$ \\
\hline$\underline{20}$ & $\underline{48.6}$ & $\underline{240.0}$ & $\underline{\mathrm{v}}$ & $\underline{14.1}$ & $\underline{3.3}$ & $=$ & $\underline{17.1}$ & $\underline{65.5}$ & $=$ & $=$ & $=$ & $\underline{2}$ & $=$ & $\underline{1}$ & $=$ & $=$ \\
\hline$\underline{21}$ & $\underline{48.6}$ & $\underline{144.7}$ & $\underline{\underline{1}}$ & $\underline{14.1}$ & $\underline{3.3}$ & $=$ & $\underline{17.1}$ & $\underline{65.5}$ & $=$ & $=$ & $=$ & $\underline{2}$ & $\underline{1}$ & $\underline{1}$ & $=$ & $=$ \\
\hline$\underline{22}$ & $\underline{48.6}$ & $\underline{113.0}$ & $\underline{\underline{L}}$ & $\underline{14.1}$ & $\underline{3.3}$ & $=$ & $\underline{17.1}$ & $\underline{65.5}$ & $=$ & $=$ & $=$ & $\underline{2}$ & $\underline{1}$ & $\underline{1}$ & $=$ & $=$ \\
\hline$\underline{23}$ & $\underline{3}$ & $\underline{106.7}$ & $\underline{\underline{L}}$ & $\underline{14.1}$ & $\underline{3.3}$ & $=$ & $\underline{17.1}$ & $\underline{65.5}$ & $=$ & $=$ & $=$ & $\underline{2}$ & $=$ & $\underline{1}$ & $=$ & $\underline{1}$ \\
\hline$\underline{24}$ & $\underline{3}$ & $\underline{141.1}$ & $\underline{\mathrm{v}}$ & $\underline{14.1}$ & $\underline{3.3}$ & $=$ & $\underline{17.1}$ & $\underline{65.5}$ & $=$ & $=$ & $=$ & $\underline{2}$ & $\underline{1}$ & $\underline{1}$ & $=$ & $=$ \\
\hline$\underline{25}$ & $\underline{3}$ & $\underline{140.2}$ & $\underline{\underline{L}}$ & $\underline{29.9}$ & $\underline{21.3}$ & $=$ & $\underline{7}$ & $\underline{41.8}$ & $=$ & $=$ & $=$ & $\underline{2}$ & $=$ & $\underline{1}$ & $=$ & $=$ \\
\hline$\underline{26}$ & $\underline{3}$ & $\underline{234.3}$ & $\underline{\mathrm{v}}$ & $\underline{29.9}$ & $\underline{21.3}$ & $=$ & $\underline{7}$ & $\underline{41.8}$ & $=$ & $=$ & $=$ & $\underline{2}$ & $\underline{1}$ & $\underline{1}$ & $=$ & $=$ \\
\hline$\underline{27}$ & $\underline{65}$ & $\underline{300.0}$ & $\underline{\mathrm{v}}$ & $\underline{5.5}$ & $\underline{2.1}$ & $\underline{0.5}$ & $=$ & $\underline{87.5}$ & $\underline{0.3}$ & $\underline{0.1}$ & $=$ & $\underline{2}$ & $=$ & $\underline{1}$ & $=$ & $=$ \\
\hline$\underline{28}$ & $\underline{65}$ & $\underline{273.0}$ & $\underline{\mathrm{v}}$ & $\underline{5.5}$ & $\underline{2.1}$ & $\underline{0.5}$ & $=$ & $\underline{87.5}$ & $\underline{0.3}$ & $\underline{0.1}$ & $=$ & $\underline{2}$ & $\underline{1}$ & $\underline{1}$ & $=$ & $=$ \\
\hline$\underline{29}$ & $\underline{65}$ & $\underline{240.0}$ & $\underline{\mathrm{v}}$ & $\underline{5.5}$ & $\underline{2.1}$ & $\underline{0.5}$ & $=$ & $\underline{87.5}$ & $\underline{0.3}$ & $\underline{0.1}$ & & $\underline{2}$ & $\underline{1}$ & $\underline{1}$ & $=$ & $=$ \\
\hline$\underline{30}$ & $\underline{65}$ & $\underline{144.7}$ & $\underline{\underline{L}}$ & $\underline{5.5}$ & $\underline{2.1}$ & $\underline{0.5}$ & $=$ & $\underline{87.5}$ & $\underline{0.3}$ & $\underline{0.1}$ & $=$ & $\underline{2}$ & $\underline{1}$ & $\underline{1}$ & $=$ & $=$ \\
\hline$\underline{31}$ & $\underline{65}$ & $\underline{113.0}$ & $\underline{\underline{L}}$ & $\underline{5.5}$ & $\underline{2.1}$ & $\underline{0.5}$ & $=$ & $\underline{87.5}$ & $\underline{0.3}$ & $\underline{0.1}$ & $=$ & $\underline{2}$ & $\underline{1}$ & $\underline{1}$ & $=$ & $=$ \\
\hline
\end{tabular}

Table 5 Result of ETA to estimate the probability of VCE.

\begin{tabular}{|c|c|c|c|c|c|c|c|c|c|c|c|c|c|c|c|c|c|c|c|c|c|c|c|c|c|c|c|}
\hline \multirow[b]{2}{*}{$\underline{G}$} & \multirow[b]{2}{*}{$\underline{\mathbf{L S}}$} & \multicolumn{5}{|c|}{ Frequency } & \multirow[b]{2}{*}{$\underline{\mathbf{G}}$} & \multirow[b]{2}{*}{$\underline{\mathbf{L S}}$} & \multicolumn{5}{|c|}{ Frequency } & \multirow[b]{2}{*}{$\underline{\mathbf{G}}$} & \multirow[b]{2}{*}{$\underline{L S}$} & \multicolumn{5}{|c|}{ Frequency } & \multirow[b]{2}{*}{$\underline{\mathbf{G}}$} & \multirow[b]{2}{*}{$\underline{\mathbf{L S}}$} & \multicolumn{5}{|c|}{ Frequency } \\
\hline & & $\underline{\text { IF }}$ & $\underline{\mathbf{I P}}$ & $\underline{\text { DP }}$ & $\underline{\text { SR }}$ & $\underline{E P}$ & & & $\underline{\text { IF }}$ & $\underline{I P}$ & $\underline{\text { DP }}$ & $\underline{\mathbf{S R}}$ & $\underline{E P}$ & & & $\underline{\mathbf{I F}}$ & $\underline{\mathbf{I P}}$ & $\underline{\text { DP }}$ & $\underline{\mathbf{S R}}$ & $\underline{E P}$ & & & $\underline{\text { IF }}$ & $\underline{\text { IP }}$ & $\underline{\text { DP }}$ & $\underline{\mathbf{S R}}$ & $\underline{\text { EP }}$ \\
\hline \multirow{4}{*}{1} & $\underline{3}$ & $3.66 \mathrm{E}-02$ & $\underline{0.9999}$ & $\underline{0.001}$ & $\underline{0.5}$ & $1.83 \mathrm{E}-05$ & \multirow{4}{*}{$\underline{9}$} & $\underline{3}$ & $7.25 \mathrm{E}-04$ & $\underline{0.9999}$ & $\underline{0.001}$ & $\underline{0.5}$ & $3.62 \mathrm{E}-07$ & \multirow{4}{*}{$\underline{17}$} & $\underline{3}$ & $3.42 \mathrm{E}-03$ & $\underline{0.9999}$ & $\underline{0.0022}$ & $\underline{0.5}$ & $3.76 \mathrm{E}-06$ & \multirow{4}{*}{25} & $\underline{3}$ & $1.69 \mathrm{E}-04$ & 0.9999 & $\underline{0.001}$ & $\underline{0.5}$ & $8.43 \mathrm{E}-08$ \\
\hline & $\underline{10}$ & $1.59 \mathrm{E}-02$ & $\underline{0.9999}$ & $\underline{0.0012}$ & $\underline{0.5}$ & $9.52 \mathrm{E}-06$ & & $\underline{10}$ & $2.41 \mathrm{E}-04$ & $\underline{0.9999}$ & $\underline{0.003}$ & $\underline{0.5}$ & $3.61 \mathrm{E}-07$ & & $\underline{10}$ & $1.88 \mathrm{E}-03$ & 0.999 & $\underline{0.0066}$ & $\underline{0.5}$ & $6.19 \mathrm{E}-06$ & & $\underline{10}$ & $6.22 \mathrm{E}-05$ & 0.9999 & $\underline{0.003}$ & $\underline{0.5}$ & $0.32 \mathrm{E}-08$ \\
\hline & $\underline{50}$ & $7.00 E-03$ & $\underline{0.999}$ & $\underline{0.0213}$ & $\underline{0.5}$ & 7.44E-05 & & $\underline{50}$ & $7.71 \mathrm{E}-05$ & $\underline{0.999}$ & $\underline{0.02}$ & 0.5 & $7.71 \mathrm{E}-07$ & & $\underline{50}$ & $1.10 \mathrm{E}-03$ & $\underline{0.99}$ & $\underline{0.028}$ & $\underline{0.5}$ & $1.52 \mathrm{E}-05$ & & $\underline{50}$ & $2.27 \mathrm{E}-05$ & $\underline{0.999}$ & $\underline{0.02}$ & $\underline{0.5}$ & $\underline{2.26 \mathrm{E}-07}$ \\
\hline & $\underline{100}$ & $2.62 \mathrm{E}-03$ & $\underline{0.99}$ & $\underline{0.15}$ & $\underline{0.5}$ & $1.95 \mathrm{E}-04$ & & $\underline{100}$ & 4.41E-05 & $\underline{0.99}$ & $\underline{0.028}$ & $\underline{0.5}$ & $6.12 \mathrm{E}-07$ & & $\underline{100}$ & $7.01 \mathrm{E}-04$ & $\underline{0.99}$ & $\underline{0.028}$ & $\underline{0.5}$ & $9.72 \mathrm{E}-06$ & & $\underline{100}$ & $\underline{2.27 E-05}$ & $\underline{0.99}$ & $\underline{0.028}$ & $\underline{0.5}$ & $3.15 \mathrm{E}-07$ \\
\hline \multirow{2}{*}{$\underline{2}$} & $\underline{3}$ & 9.68E-04 & $\underline{0.9999}$ & $\underline{0.0022}$ & $\underline{0.5}$ & $1.06 \mathrm{E}-06$ & \multirow{2}{*}{$\underline{10}$} & $\underline{3}$ & $9.68 \mathrm{E}-04$ & $\underline{0.9999}$ & $\underline{0.001}$ & $\underline{0.5}$ & $4.84 \mathrm{E}-07$ & \multirow{2}{*}{$\underline{18}$} & $\underline{3}$ & $9.68 \mathrm{E}-04$ & $\underline{0.9999}$ & $\underline{0.0022}$ & $\underline{0.5}$ & $1.06 \mathrm{E}-06$ & \multirow{2}{*}{$\underline{26}$} & $\underline{3}$ & 9.68E-04 & $\underline{0.9999}$ & $\underline{0.001}$ & $\underline{0.5}$ & $4.84 \mathrm{E}-07$ \\
\hline & $\underline{10}$ & $4.42 E-04$ & 0.999 & $\underline{0.0066}$ & $\underline{0.5}$ & $1.46 \mathrm{E}-06$ & & $\underline{10}$ & $4.42 \mathrm{E}-04$ & $\underline{0.9999}$ & $\underline{0.001}$ & $\underline{0.5}$ & $2.21 \mathrm{E}-07$ & & $\underline{10}$ & $4.42 \mathrm{E}-04$ & 0.999 & $\underline{0.0066}$ & $\underline{0.5}$ & $1.46 \mathrm{E}-06$ & & $\underline{10}$ & $4.42 \mathrm{E}-04$ & $\underline{0.9999}$ & $\underline{0.001}$ & $\underline{0.5}$ & $\underline{2.21 \mathrm{E}-07}$ \\
\hline
\end{tabular}




\begin{tabular}{|c|c|c|c|c|c|c|c|c|c|c|c|c|c|}
\hline & $\underline{50}$ & $2.09 \mathrm{E}-04$ & 0.99 & $\underline{0.028}$ & $\underline{0.5}$ & $2.90 \mathrm{E}-06$ & & $\underline{50}$ & $2.09 \mathrm{E}-04$ & 0.9999 & $\underline{0.0013}$ & $\underline{0.5}$ & $1.36 \mathrm{E}-07$ \\
\hline & 100 & $1.06 \mathrm{E}-04$ & 0.99 & $\begin{array}{ll}0.028 \\
\end{array}$ & 0.5 & $1.47 \mathrm{E}-06$ & & 100 & $1.06 \mathrm{E}-04$ & 0.999 & 0.0092 & 0.5 & $4.88 \mathrm{E}-07$ \\
\hline \multirow{4}{*}{$\underline{3}$} & $\underline{3}$ & $9.68 \mathrm{E}-04$ & 0.9999 & $\underline{0.0022}$ & $\underline{0.5}$ & $1.06 \mathrm{E}-06$ & \multirow{4}{*}{$\underline{11}$} & $\underline{3}$ & $3.66 \mathrm{E}-02$ & 0.9999 & $\underline{0.001}$ & $\underline{0.5}$ & $1.83 \mathrm{E}-05$ \\
\hline & $\underline{10}$ & $4.42 \mathrm{E}-04$ & 0.999 & 0.0066 & 0.5 & $1.46 \mathrm{E}-06$ & & $\underline{10}$ & $1.59 \mathrm{E}-02$ & 0.9999 & 0.001 & 0.5 & $7.94 \mathrm{E}-06$ \\
\hline & $\underline{50}$ & $2.09 \mathrm{E}-04$ & 0.99 & $\underline{0.028}$ & 0.5 & $2.90 \mathrm{E}-06$ & & $\underline{50}$ & $7.00 \mathrm{E}-03$ & 0.999 & $\underline{0.0092}$ & 0.5 & $3.21 \mathrm{E}-0.5$ \\
\hline & 100 & $1.06 \mathrm{E}-04$ & 0.99 & 0.028 & 0.5 & $1.47 E-06$ & & 100 & $2.62 \mathrm{E}-03$ & 0.999 & 0.0213 & 0.5 & $2.79 \mathrm{E}-05$ \\
\hline \multirow{4}{*}{4} & $\underline{3}$ & $3.66 \mathrm{E}-02$ & 0.9999 & 0.0022 & 0.5 & $4.02 E-05$ & \multirow{4}{*}{12} & $\underline{3}$ & $1.69 \mathrm{E}-04$ & 0.9999 & $\underline{0.001}$ & 0.5 & $8.45 \mathrm{E}-08$ \\
\hline & 10 & $1.59 \mathrm{E}-02$ & 0.999 & 0.0066 & 0.5 & $5.23 \mathrm{E}-05$ & & $\underline{10}$ & $1.59 \mathrm{E}-02$ & 0.9999 & 0.001 & 0.5 & $7.94 \mathrm{E}-06$ \\
\hline & $\underline{50}$ & $7.00 \mathrm{E}-03$ & 0.99 & 0.028 & 0.5 & $9.70 \mathrm{E}-05$ & & $\underline{50}$ & $7.00 \mathrm{E}-03$ & 0.999 & 0.0092 & 0.5 & $3.21 \mathrm{E}-05$ \\
\hline & 100 & $2.62 \mathrm{E}-03$ & 0.99 & $\underline{0.028}$ & 0.5 & $3.63 \mathrm{E}-05$ & & 100 & $2.62 \mathrm{E}-03$ & 0.999 & $\underline{0.0213}$ & 0.5 & $2.79 \mathrm{E}-05$ \\
\hline \multirow{4}{*}{$\underline{\underline{5}}$} & $\underline{3}$ & $7.25 \mathrm{E}-04$ & $\underline{0.9999}$ & 0.0014 & 0.5 & $5.077-07$ & \multirow{4}{*}{$\underline{13}$} & $\underline{3}$ & $3.66 \mathrm{E}-02$ & $\underline{0.9999}$ & $\underline{0.001}$ & $\underline{0.5}$ & $1.83 \mathrm{E}-0.5$ \\
\hline & $\underline{10}$ & $2.41 \mathrm{E}-04$ & 0.999 & 0.0042 & 0.5 & $5.06 \mathrm{E}-07$ & & $\underline{10}$ & $1.59 \mathrm{E}-02$ & 0.9999 & 0.0012 & 0.5 & $9.52 \mathrm{E}-06$ \\
\hline & $\underline{50}$ & $7.71 \mathrm{E}-0.5$ & 0.99 & 0.02 & 0.5 & 7.64E- -07 & & $\underline{50}$ & $7.00 \mathrm{E}-03$ & 0.99 & $\underline{0.0493}$ & 0.5 & $1.71 \mathrm{E}-04$ \\
\hline & 100 & $4.41 \mathrm{E}-05$ & 0.99 & $\begin{array}{ll}0.028 \\
\end{array}$ & 0.5 & $6.12 \mathrm{E}-07$ & & 100 & $2.62 \mathrm{E}-03$ & 0.99 & 0.15 & 0.5 & $1.95 \mathrm{E}-04$ \\
\hline \multirow{4}{*}{$\underline{6}$} & $\underline{3}$ & $9.68 \mathrm{E}-04$ & 0.9999 & $\underline{0.001}$ & 0.5 & $4.84 \mathrm{E}-07$ & \multirow{4}{*}{14} & $\underline{3}$ & $9.68 \mathrm{E}-04$ & 0.9999 & $\underline{0.001}$ & 0.5 & $4.84 \mathrm{E}-07$ \\
\hline & $\underline{10}$ & $4.42 E-04$ & $\underline{0.9999}$ & 0.001 & 0.5 & $2.21 \mathrm{E}-07$ & & $\underline{10}$ & $4.42 E-04$ & $\underline{0.9999}$ & $\underline{0.0012}$ & $\underline{0.5}$ & $2.65 \mathrm{E}-07$ \\
\hline & $\underline{50}$ & $2.09 \mathrm{E}-04$ & 0.999 & 0.0092 & 0.5 & $9.62 \mathrm{E}-07$ & & $\underline{50}$ & $2.09 \mathrm{E}-04$ & 0.99 & 0.0493 & 0.5 & $5.11 \mathrm{E}-06$ \\
\hline & $\underline{100}$ & $1.06 \mathrm{E}-04$ & $\underline{0.999}$ & $\underline{0.0213}$ & 0.5 & $1.13 \mathrm{E}-06$ & & $\underline{100}$ & $1.06 \mathrm{E}-04$ & $\underline{0.99}$ & $\underline{0.15}$ & $\underline{0.5}$ & $7.88 \mathrm{E}-06$ \\
\hline \multirow{4}{*}{$\underline{7}$} & $\underline{3}$ & $1.69 \mathrm{E}-04$ & $\underline{0.9999}$ & 0.0022 & 0.5 & $1.85 \mathrm{E}-07$ & \multirow{4}{*}{$\underline{15}$} & $\underline{3}$ & $9.68 \mathrm{E}-04$ & 0.9999 & $\underline{0.001}$ & 0.5 & $4.84 \mathrm{E}-07$ \\
\hline & 10 & $6.22 \mathrm{E}-0.5$ & 0.999 & 0.0066 & 0.5 & $2.05 E-07$ & & $\underline{10}$ & $4.42 \mathrm{E}-04$ & 0.9999 & 0.0013 & 0.5 & $2.88 \mathrm{E}-07$ \\
\hline & $\underline{50}$ & $2.27 \mathrm{E}-05$ & 0.99 & 0.028 & 0.5 & $3.14 \mathrm{E}-07$ & & $\underline{50}$ & $2.09 \mathrm{E}-04$ & 0.99 & 0.0493 & 0.5 & $5.11 \mathrm{E}-06$ \\
\hline & 100 & $2.27 \mathrm{E}-0.5$ & 0.99 & 0.028 & 0.5 & $3.15 E-07$ & & 100 & $1.06 \mathrm{E}-04$ & 0.99 & $\begin{array}{l}0.15 \\
.15\end{array}$ & 0.5 & $7.88 \mathrm{E}-06$ \\
\hline \multirow{4}{*}{$\underline{8}$} & $\underline{3}$ & $9.68 \mathrm{E}-04$ & 0.9999 & 0.0022 & 0.5 & $1.06 \mathrm{E}-06$ & \multirow{4}{*}{$\underline{16}$} & $\underline{3}$ & $9.68 \mathrm{E}-04$ & 0.9999 & $\underline{0.0022}$ & 0.5 & $1.06 \mathrm{E}-06$ \\
\hline & $\underline{10}$ & $4.42 \mathrm{E}-04$ & $\underline{0.999}$ & $\underline{0.0066}$ & $\underline{0.5}$ & $1.46 \mathrm{E}-06$ & & $\underline{10}$ & 4.422E-04 & $\underline{0.999}$ & $\underline{0.0066}$ & $\underline{0.5}$ & $1.46 \mathrm{E}-06$ \\
\hline & $\underline{50}$ & $2.09 \mathrm{E}-04$ & 0.99 & 0.028 & 0.5 & $2.90 \mathrm{E}-06$ & & $\underline{50}$ & $2.09 \mathrm{E}-04$ & 0.99 & 0.028 & 0.5 & $2.90 \mathrm{E}-06$ \\
\hline & 100 & $1.06 \mathrm{E}-04$ & 0.99 & 0.028 & 0.5 & $1.47 \mathrm{E}-06$ & & 100 & $1.06 \mathrm{E}-04$ & 0.99 & 0.028 & 0.5 & $1.47 \mathrm{E}-06$ \\
\hline
\end{tabular}

\begin{tabular}{|c|c|c|c|c|c|}
\hline$\underline{50}$ & $2.09 E-04$ & $\underline{0.99}$ & $\underline{0.028}$ & $\underline{0.5}$ & $2.90 \mathrm{E}-06$ \\
\hline 100 & $1.06 \mathrm{E}-04$ & $\underline{0.99}$ & $\underline{0.028}$ & $\underline{0.5}$ & $1.47 \mathrm{E}-06$ \\
\hline$\underline{3}$ & $7.25 \mathrm{E}-04$ & 0.9999 & $\underline{0.001}$ & $\underline{0.5}$ & $3.62 \mathrm{E}-07$ \\
\hline$\underline{10}$ & $\underline{2.41 E-04}$ & $\underline{0.9999}$ & $\underline{0.003}$ & $\underline{0.5}$ & $3.61 \mathrm{E}-07$ \\
\hline$\underline{50}$ & $7.71 \mathrm{E}-05$ & $\underline{0.999}$ & $\underline{0.02}$ & $\underline{0.5}$ & $7.71 \mathrm{E}-07$ \\
\hline$\underline{100}$ & $4.41 E-05$ & $\underline{0.99}$ & $\underline{0.028}$ & $\underline{0.5}$ & $6.12 \mathrm{E}-07$ \\
\hline$\underline{3}$ & $1.69 E-04$ & 0.9999 & $\underline{0.001}$ & $\underline{0.5}$ & $8.43 \mathrm{E}-08$ \\
\hline$\underline{10}$ & $\begin{array}{l}6.22 \mathrm{E}-05 \\
\end{array}$ & $\underline{0.9999}$ & $\underline{0.0013}$ & $\underline{0.5}$ & $4.04 \mathrm{E}-08$ \\
\hline$\underline{50}$ & $\underline{2.27 E-05}$ & $\underline{0.99}$ & $\underline{0.0493}$ & $\underline{0.5}$ & $5.53 \mathrm{E}-07$ \\
\hline$\underline{100}$ & $\underline{2.27 E-05}$ & $\underline{0.99}$ & $\underline{0.15}$ & $\underline{0.5}$ & $1.69 \mathrm{E}-06$ \\
\hline$\underline{3}$ & 2.68E-04 & $\underline{0.9999}$ & $\underline{0.0022}$ & $\underline{0.5}$ & $1.06 \mathrm{E}-06$ \\
\hline$\underline{10}$ & $4.42 \mathrm{E}-04$ & $\underline{0.999}$ & $\underline{0.0066}$ & $\underline{0.5}$ & $1.46 \mathrm{E}-06$ \\
\hline$\underline{50}$ & $2.09 E-04$ & $\underline{0.99}$ & $\underline{0.028}$ & $\underline{0.5}$ & $2.90 \mathrm{E}-06$ \\
\hline$\underline{100}$ & $1.06 \mathrm{E}-04$ & $\underline{0.99}$ & $\underline{0.028}$ & $\underline{0.5}$ & $1.47 \mathrm{E}-06$ \\
\hline$\underline{3}$ & 9.68E-04 & 0.9999 & $\underline{0.0022}$ & $\underline{0.5}$ & $1.06 \mathrm{E}-06$ \\
\hline$\underline{10}$ & $4.42 \mathrm{E}-04$ & $\underline{0.999}$ & $\underline{0.0066}$ & $\underline{0.5}$ & $1.46 \mathrm{E}-06$ \\
\hline$\underline{50}$ & $\underline{2.09 E-04}$ & $\underline{0.99}$ & $\underline{0.028}$ & $\underline{0.5}$ & $2.90 \mathrm{E}-06$ \\
\hline$\underline{100}$ & $1.06 \mathrm{E}-04$ & $\underline{0.99}$ & $\underline{0.028}$ & $\underline{0.5}$ & $1.47 \mathrm{E}-06$ \\
\hline$\underline{3}$ & $7.25 \mathrm{E}-04$ & $\underline{0.9999}$ & $\underline{0.001}$ & $\underline{0.5}$ & $3.62 \mathrm{E}-07$ \\
\hline$\underline{10}$ & $\underline{2.41 E-04}$ & $\underline{0.9999}$ & $\underline{0.003}$ & $\underline{0.5}$ & $3.61 \mathrm{E}-07$ \\
\hline$\underline{50}$ & $7.71 E-05$ & $\underline{0.999}$ & $\underline{0.02}$ & $\underline{0.5}$ & $7.71 \mathrm{E}-07$ \\
\hline$\underline{100}$ & $4.41 \mathrm{E}-05$ & $\underline{0.99}$ & $\underline{0.028}$ & $\underline{0.5}$ & $6.12 \mathrm{E}-07$ \\
\hline$\underline{3}$ & 2.68E-04 & $\underline{0.9999}$ & $\underline{0.001}$ & $\underline{0.5}$ & $4.84 \mathrm{E}-07$ \\
\hline$\underline{10}$ & $4.42 \mathrm{E}-04$ & 0.9999 & $\underline{0.001}$ & $\underline{0.5}$ & $2.21 \mathrm{E}-07$ \\
\hline$\underline{50}$ & $2.09 E-04$ & $\underline{0.999}$ & $\underline{0.003}$ & $\underline{0.5}$ & $3.14 \mathrm{E}-07$ \\
\hline 100 & $1.06 \mathrm{E}-04$ & $\underline{0.999}$ & $\underline{0.0092}$ & $\underline{0.5}$ & $4.88 \mathrm{E}-07$ \\
\hline
\end{tabular}

\begin{tabular}{|c|c|c|c|c|c|}
\hline$\underline{50}$ & $\underline{2.09 \mathrm{E}-04}$ & $\underline{0.9999}$ & $\underline{0.0013}$ & $\underline{0.5}$ & $\underline{1.36 \mathrm{E}-07}$ \\
\hline$\underline{100}$ & $\underline{1.06 \mathrm{E}-04}$ & $\underline{0.999}$ & $\underline{0.0092}$ & $\underline{0.5}$ & $\underline{4.88 \mathrm{E}-07}$ \\
\hline$\underline{3}$ & $\underline{1.69 \mathrm{E}-04}$ & $\underline{0.9999}$ & $\underline{0.001}$ & $\underline{0.5}$ & $\underline{8.43 \mathrm{E}-08}$ \\
\hline$\underline{10}$ & $\underline{6.22 \mathrm{E}-0.5}$ & $\underline{0.9999}$ & $\underline{0.0013}$ & $\underline{0.5}$ & $\underline{4.04 \mathrm{E}-08}$ \\
\hline$\underline{50}$ & $\underline{2.27 \mathrm{E}-05}$ & $\underline{0.99}$ & $\underline{0.0493}$ & $\underline{0.5}$ & $\underline{5.53 \mathrm{E}-07}$ \\
\hline$\underline{100}$ & $\underline{2.27 \mathrm{E}-05}$ & $\underline{0.99}$ & $\underline{0.15}$ & $\underline{0.5}$ & $\underline{1.69 \mathrm{E}-06}$ \\
\hline$\underline{3}$ & $\underline{9.68 \mathrm{E}-04}$ & $\underline{0.9999}$ & $\underline{0.001}$ & $\underline{0.5}$ & $\underline{4.84 \mathrm{E}-07}$ \\
\hline$\underline{10}$ & $\underline{4.42 \mathrm{E}-04}$ & $\underline{0.9999}$ & $\underline{0.0013}$ & $\underline{0.5}$ & $\underline{2.88 \mathrm{E}-07}$ \\
\hline$\underline{50}$ & $\underline{2.09 \mathrm{E}-04}$ & $\underline{0.99}$ & $\underline{0.0493}$ & $\underline{0.5}$ & $\underline{5.11 \mathrm{E}-06}$ \\
\hline$\underline{100}$ & $\underline{1.06 \mathrm{E}-04}$ & $\underline{0.99}$ & $\underline{0.15}$ & $\underline{0.5}$ & $\underline{7.88 \mathrm{E}-06}$ \\
\hline$\underline{3}$ & $\underline{9.68 \mathrm{E}-04}$ & $\underline{0.9999}$ & $\underline{0.001}$ & $\underline{0.5}$ & $\underline{4.84 \mathrm{E}-07}$ \\
\hline$\underline{10}$ & $\underline{4.42 \mathrm{E}-04}$ & $\underline{0.9999}$ & $\underline{0.0013}$ & $\underline{0.5}$ & $\underline{2.88 \mathrm{E}-07}$ \\
\hline$\underline{50}$ & $\underline{2.09 \mathrm{E}-04}$ & $\underline{0.99}$ & $\underline{0.0493}$ & $\underline{0.5}$ & $\underline{5.11 \mathrm{E}-06}$ \\
\hline$\underline{100}$ & $\underline{1.066-04}$ & $\underline{0.99}$ & $\underline{0.15}$ & $\underline{0.5}$ & $\underline{7.88 \mathrm{E}-06}$ \\
\hline$\underline{3}$ & $\underline{9.68 \mathrm{E}-04}$ & $\underline{0.9999}$ & $\underline{0.001}$ & $\underline{0.5}$ & $\underline{4.84 \mathrm{E}-07}$ \\
\hline$\underline{10}$ & $\underline{4.42 \mathrm{E}-04}$ & $\underline{0.9999}$ & $\underline{0.0014}$ & $\underline{0.5}$ & $\underline{3.10 \mathrm{E}-07}$ \\
\hline$\underline{50}$ & $\underline{2.09 \mathrm{E}-04}$ & $\underline{0.999}$ & $\underline{0.0066}$ & $\underline{0.5}$ & $\underline{6.90 \mathrm{E}-07}$ \\
\hline$\underline{100}$ & $\underline{1.06 \mathrm{E}-04}$ & $\underline{0.999}$ & $\underline{0.0129}$ & $\underline{0.5}$ & $\underline{6.84 \mathrm{E}-07}$ \\
\hline$\underline{3}$ & $\underline{9.68 \mathrm{E}-04}$ & $\underline{0.9999}$ & $\underline{0.001}$ & $\underline{0.5}$ & $\underline{4.84 \mathrm{E}-07}$ \\
\hline$\underline{10}$ & $\underline{4.42 \mathrm{E}-04}$ & $\underline{0.9999}$ & $\underline{0.0014}$ & $\underline{0.5}$ & $\underline{3.10 \mathrm{E}-07}$ \\
\hline$\underline{50}$ & $\underline{2.09 \mathrm{E}-04}$ & $\underline{0.999}$ & $\underline{0.0066}$ & $\underline{0.5}$ & $\underline{6.90 \mathrm{E}-07}$ \\
\hline$\underline{100}$ & $\underline{1.06 \mathrm{E}-04}$ & $\underline{0.999}$ & $\underline{0.0129}$ & $\underline{0.5}$ & $\underline{6.84 \mathrm{E}-07}$ \\
\hline & & & & & \\
\hline & & & & & \\
\hline & & & & & \\
\hline & & & & & \\
\hline & & & & & \\
\hline & & & & & \\
\hline & & & & \\
\hline
\end{tabular}

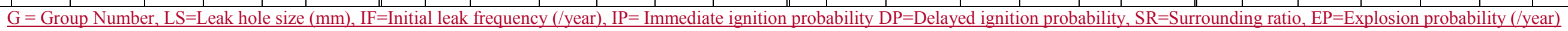


Table 6 Leak rate for various leak hole sizes.

\begin{tabular}{|c|c|c|c|c|c|c|c|c|c|}
\hline \multirow{2}{*}{$\frac{\text { Grou }}{\underline{\mathrm{p}}}$} & \multicolumn{4}{|c|}{ Leakage rate $(\mathrm{kg} / \mathrm{s})$} & \multirow{2}{*}{$\frac{\text { Grou }}{\underline{p}}$} & \multicolumn{4}{|c|}{ Leakage rate $(\mathrm{kg} / \mathrm{s})$} \\
\hline & $\underline{3 \mathrm{~mm}}$ & $\frac{10 \mathrm{~m}}{\underline{m}}$ & $\frac{50 \mathrm{~m}}{\underline{m}}$ & $\frac{100 \mathrm{~m}}{\mathrm{~m}}$ & & $\underline{3 \mathrm{~mm}}$ & $\frac{10 \mathrm{~m}}{\underline{m}}$ & $\frac{50 \mathrm{~m}}{\underline{m}}$ & $\frac{100 \mathrm{~m}}{\mathrm{~m}}$ \\
\hline$\underline{1}$ & $\underline{0.02}$ & $\underline{0.22}$ & $\underline{5.55}$ & $\underline{22.20}$ & $\underline{17}$ & $\underline{0.31}$ & 3.42 & $\underline{85.44}$ & 341.75 \\
\hline$\underline{2}$ & $\underline{0.20}$ & 2.25 & $\underline{56.22}$ & $\underline{224.89}$ & $\underline{18}$ & $\underline{0.31}$ & $\underline{3.42}$ & $\underline{85.44}$ & 341.75 \\
\hline$\underline{3}$ & $\underline{0.20}$ & $\underline{2.25}$ & $\underline{56.22}$ & $\underline{224.89}$ & $\underline{19}$ & $\underline{0.08}$ & $\underline{0.85}$ & $\underline{21.23}$ & $\underline{84.91}$ \\
\hline$\underline{4}$ & $\underline{0.20}$ & $\underline{2.25}$ & $\underline{56.22}$ & $\underline{224.89}$ & $\underline{20}$ & $\underline{0.05}$ & $\underline{0.50}$ & $\underline{12.61}$ & $\underline{50.42}$ \\
\hline$\underline{5}$ & $\underline{0.13}$ & 1.41 & 35.37 & 141.49 & $\underline{21}$ & $\underline{0.30}$ & 3.37 & $\underline{84.30}$ & 337.21 \\
\hline$\underline{6}$ & $\underline{0.01}$ & $\underline{0.10}$ & $\underline{2.38}$ & $\underline{9.50}$ & $\underline{22}$ & $\underline{0.30}$ & 3.37 & $\underline{84.30}$ & 337.21 \\
\hline$\underline{7}$ & $\underline{0.20}$ & $\underline{2.25}$ & $\underline{56.22}$ & $\underline{224.89}$ & $\underline{23}$ & $\underline{0.08}$ & $\underline{0.84}$ & $\underline{20.94}$ & $\underline{83.78}$ \\
\hline$\underline{8}$ & $\underline{0.20}$ & $\underline{2.25}$ & $\underline{56.22}$ & $\underline{224.89}$ & $\underline{24}$ & $\underline{0.01}$ & $\underline{0.04}$ & 1.01 & $\underline{4.06}$ \\
\hline$\underline{9}$ & $\underline{0.08}$ & $\underline{0.86}$ & 21.47 & 85.88 & $\underline{25}$ & $\underline{0.08}$ & $\underline{0.85}$ & $\underline{21.14}$ & 84.54 \\
\hline$\underline{10}$ & $\underline{0.00}$ & $\underline{0.04}$ & $\underline{0.93}$ & $\underline{3.72}$ & $\underline{26}$ & $\underline{0.00}$ & $\underline{0.04}$ & 0.88 & 3.52 \\
\hline$\underline{11}$ & $\underline{0.01}$ & $\underline{0.09}$ & $\underline{2.34}$ & $\underline{9.34}$ & $\underline{27}$ & $\underline{0.05}$ & $\underline{0.53}$ & $\underline{13.30}$ & $\underline{53.19}$ \\
\hline$\underline{12}$ & $\underline{0.01}$ & $\underline{0.09}$ & $\underline{2.36}$ & 9.42 & $\underline{28}$ & $\underline{0.05}$ & $\underline{0.56}$ & 13.94 & $\underline{55.76}$ \\
\hline$\underline{13}$ & $\underline{0.04}$ & $\underline{0.43}$ & 10.71 & $\underline{42.82}$ & $\underline{29}$ & $\underline{0.05}$ & $\underline{0.59}$ & 14.87 & $\underline{59.47}$ \\
\hline$\underline{14}$ & $\underline{0.04}$ & $\underline{0.50}$ & 12.49 & $\underline{49.95}$ & $\underline{30}$ & $\underline{0.01}$ & $\underline{0.15}$ & $\underline{3.70}$ & $\underline{14.79}$ \\
\hline$\underline{15}$ & $\underline{0.05}$ & $\underline{0.53}$ & $\underline{13.20}$ & $\underline{52.78}$ & $\underline{31}$ & $\underline{0.01}$ & $\underline{0.15}$ & $\underline{3.70}$ & $\underline{14.79}$ \\
\hline$\underline{16}$ & $\underline{0.31}$ & $\underline{3.40}$ & $\underline{85.07}$ & 340.27 & & & & & \\
\hline
\end{tabular}


Table 7 Estimated explosion pressure in accordance with the safety gaps.

\begin{tabular}{|c|c|c|c|c|}
\hline Specification & Methods & Case 1 & Case 2 & Case 3 \\
\hline $\begin{array}{l}\text { Distance from the ignition point } \\
\text { (Equivalent to safety gap) }\end{array}$ & & $20 \mathrm{~m}$ & $15 \mathrm{~m}$ & $12.5 \mathrm{~m}$ \\
\hline \multirow{3}{*}{ Explosion pressures } & TNT & $0.77 \mathrm{bar}$ & $1.24 \mathrm{bar}$ & $1.82 \mathrm{bar}$ \\
\hline & TNO & $1.0 \mathrm{bar}$ & $1.0 \mathrm{bar}$ & $1.0 \mathrm{bar}$ \\
\hline & BST & 0.7 bar & $1.0 \mathrm{bar}$ & $1.0 \mathrm{bar}$ \\
\hline
\end{tabular}


Table 8 I-Beam sizes used in the modules (DSME, 2013b).

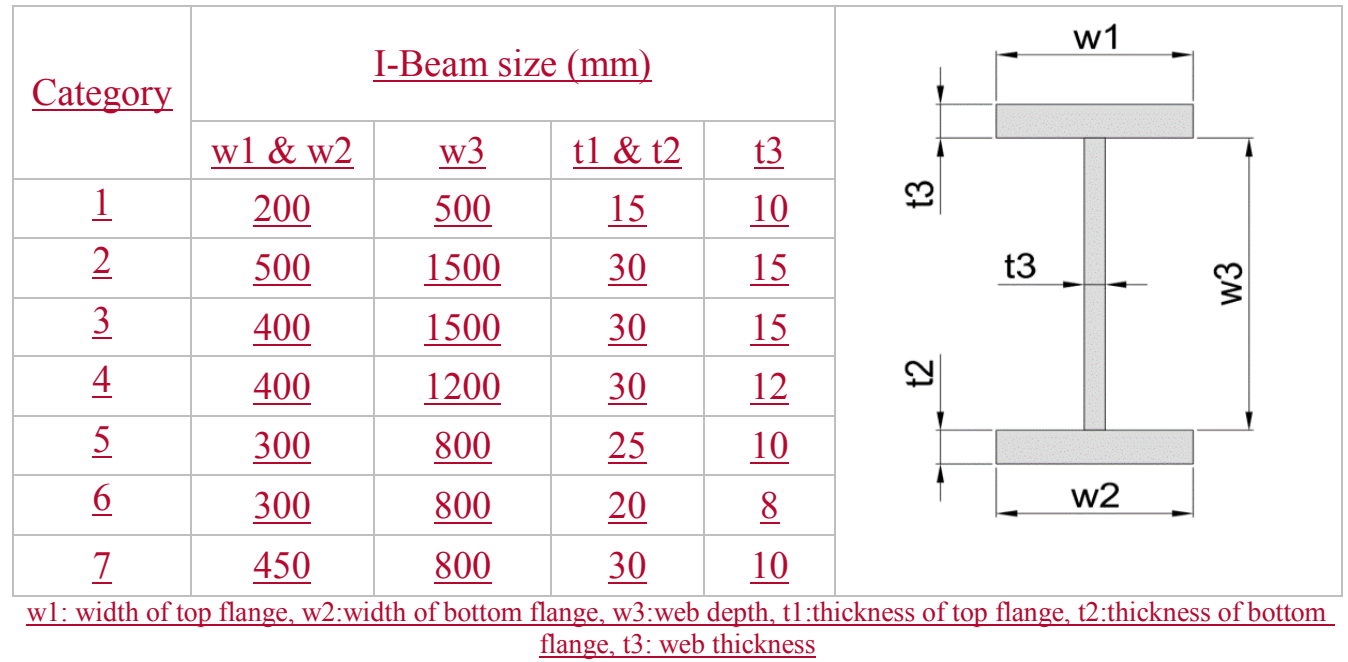


$\underline{\text { Table } 9 \text { Estimated explosion pressure for various safety gaps. }}$

\begin{tabular}{|c|c|c|c|}
\hline Method & $\begin{array}{c}\text { Safety gap } \\
\text { (m) }\end{array}$ & $\frac{\text { Applied pressure }}{(\text { Bar) }}$ & $\begin{array}{l}\text { Max. equivalent } \\
\text { stress }\left(\mathrm{N} / \mathrm{mm}^{2}\right)\end{array}$ \\
\hline \multirow{3}{*}{$\underline{\text { TNT }}$} & 20.0 & $\underline{0.77}$ & $\underline{526.6}$ \\
\hline & $\underline{15.0}$ & $\underline{1.24}$ & $\underline{873.9}$ \\
\hline & $\underline{12.5}$ & 1.82 & $\underline{1480.5}$ \\
\hline \multirow{3}{*}{$\underline{\text { TNO }}$} & $\underline{20.0}$ & $\underline{1.0}$ & $\underline{683.8}$ \\
\hline & $\underline{15.0}$ & $\underline{1.0}$ & 705.6 \\
\hline & $\underline{12.5}$ & 1.0 & 813.9 \\
\hline \multirow{3}{*}{$\underline{B S T}$} & $\underline{20.0}$ & $\underline{0.7}$ & 478.7 \\
\hline & $\underline{15.0}$ & $\underline{1.0}$ & $\underline{705.6}$ \\
\hline & $\underline{12.5}$ & $\underline{1.0}$ & $\underline{813.9}$ \\
\hline
\end{tabular}


Table 10 List of pipe sizes.

\begin{tabular}{|c|c|c|c|}
\hline \multirow[t]{2}{*}{ Category } & \multicolumn{2}{|c|}{$\frac{\text { Pipe size }}{\text { (sectional area }}$} & \multirow[t]{9}{*}{ t4 } \\
\hline & Dia. & $\underline{\mathrm{t} 4}$ & \\
\hline$\underline{1}$ & $\underline{194 \mathrm{~mm}}$ & $\underline{20 \mathrm{~mm}}$ & \\
\hline$\underline{2}$ & $\underline{856 \mathrm{~mm}}$ & $20 \mathrm{~mm}$ & \\
\hline$\underline{3}$ & $\underline{760 \mathrm{~mm}}$ & $\underline{20 \mathrm{~mm}}$ & \\
\hline$\underline{4}$ & $\underline{536 \mathrm{~mm}}$ & $\underline{20 \mathrm{~mm}}$ & \\
\hline$\underline{5}$ & $\underline{386 \mathrm{~mm}}$ & $\underline{20 \mathrm{~mm}}$ & \\
\hline$\underline{6}$ & $312 \mathrm{~mm}$ & $\underline{20 \mathrm{~mm}}$ & \\
\hline 7 & $576 \mathrm{~mm}$ & $20 \mathrm{~mm}$ & \\
\hline
\end{tabular}


$\underline{\text { Table } 11 \text { Equivalent stresses for I-beam and pipe structures. }}$

\begin{tabular}{|c|c|c|c|c|c|}
\hline \multirow[t]{2}{*}{ Method } & \multirow{2}{*}{$\frac{\text { Safety }}{\text { gap (m) }}$} & \multirow{2}{*}{$\frac{\underline{\text { Applied }}}{\text { pressure }}$} & \multicolumn{2}{|c|}{ Max. equivalent stress $\left(\mathrm{N} / \mathrm{mm}^{2}\right)$} & \multirow{2}{*}{$\frac{\text { Reduced rate }}{\underline{(\%)}}$} \\
\hline & & & $\underline{\text { Beam structure }}$ & $\underline{\text { Pipe structure }}$ & \\
\hline \multirow[t]{3}{*}{$\underline{\mathrm{TNT}}$} & $\underline{20}$ & $\underline{0.77}$ & $\underline{526.5}$ & $\underline{219.3}$ & $\underline{57}$ \\
\hline & $\underline{15}$ & 1.24 & $\underline{873.9}$ & 282.5 & $\underline{67}$ \\
\hline & $\underline{12.5}$ & 1.82 & $\underline{1,480.5}$ & 317.1 & $\underline{78}$ \\
\hline \multirow[t]{3}{*}{$\underline{\mathrm{TNO}}$} & $\underline{20}$ & $\underline{1.0}$ & $\underline{683.8}$ & $\underline{221.3}$ & $\underline{68}$ \\
\hline & $\underline{15}$ & $\underline{1.0}$ & 705.6 & 269.1 & $\underline{62}$ \\
\hline & $\underline{12.5}$ & $\underline{1.0}$ & $\underline{813.9}$ & 220.9 & $\underline{73}$ \\
\hline \multirow[t]{3}{*}{$\underline{\mathrm{BST}}$} & $\underline{20}$ & $\underline{0.7}$ & $\underline{478.6}$ & $\underline{218.8}$ & $\underline{54}$ \\
\hline & $\underline{15}$ & $\underline{1.0}$ & $\underline{705.6}$ & 269.1 & $\underline{62}$ \\
\hline & $\underline{12.5}$ & $\underline{1.0}$ & $\underline{813.9}$ & $\underline{220.9}$ & $\underline{73}$ \\
\hline
\end{tabular}

